\title{
PINK1/PARKIN signalling in neurodegeneration and neuroinflammation
}

\author{
Peter M. J. Quinn ${ }^{1,2}$, Paula I. Moreira $3,4,5$, António Francisco Ambrósio $4,6,7,8$ and C. Henrique Alves $4,6,7,8^{*}$ (D)
}

\begin{abstract}
Mutations in the PTEN-induced kinase 1 (PINK1) and Parkin RBR E3 ubiquitin-protein ligase (PARKIN) genes are associated with familial forms of Parkinson's disease (PD). PINK1, a protein kinase, and PARKIN, an E3 ubiquitin ligase, control the specific elimination of dysfunctional or superfluous mitochondria, thus fine-tuning mitochondrial network and preserving energy metabolism. PINK1 regulates PARKIN translocation in impaired mitochondria and drives their removal via selective autophagy, a process known as mitophagy. As knowledge obtained using different PINK1 and PARKIN transgenic animal models is being gathered, growing evidence supports the contribution of mitophagy impairment to several human pathologies, including PD and Alzheimer's diseases (AD). Therefore, therapeutic interventions aiming to modulate PINK1/PARKIN signalling might have the potential to treat these diseases. In this review, we will start by discussing how the interplay of PINK1 and PARKIN signalling helps mediate mitochondrial physiology. We will continue by debating the role of mitochondrial dysfunction in disorders such as amyotrophic lateral sclerosis, Alzheimer's, Huntington's and Parkinson's diseases, as well as eye diseases such as age-related macular degeneration and glaucoma, and the causative factors leading to PINK1/PARKIN-mediated neurodegeneration and neuroinflammation. Finally, we will discuss PINK1/PARKIN gene augmentation possibilities with a particular focus on AD, PD and glaucoma.
\end{abstract}

Keywords: PINK1, PARKIN, Mitophagy, Neurodegeneration, Alzheimer's disease, Parkinson's disease

\section{Background}

Mitochondria, first discovered in the late $19^{\text {th }}$ century, are considered key for cellular bioenergetics $[1,2]$. They consist of a double membrane with an intermembrane space. The inner membrane forms folds called cristae which provide an increased surface area for chemical and redox reactions to take place [3-5]. Mitochondria produce the majority of cellular adenosine triphosphate (ATP) through oxidative phosphorylation (OXPHOS). The protein complexes (cI-IV) of the respiratory chain transfer electrons from NADH and $\mathrm{FADH}_{2}$ (provided by the Krebs cycle) to molecular $\mathrm{O}_{2}$, a process also known as the electron transport chain (ETC). The ETC creates

\footnotetext{
${ }^{*}$ Correspondence: chalves@fmed.uc.pt

${ }^{6}$ Coimbra Institute for Clinical and Biomedical Research (iCBR), Faculty of Medicine, University of Coimbra, Coimbra, Portugal

Full list of author information is available at the end of the article
}

a membrane potential $(\Delta \Psi \mathrm{m})$ across the mitochondrial inner membrane by pumping protons from the mitochondrial matrix to the intermembrane space, thus creating a high concentration of protons in the intermembrane space and a low concentration in the mitochondrial matrix. Subsequently, along this chemiosmotic gradient, the protons move back into the mitochondrial matrix, via ATP synthase $(\mathrm{cV})$. ATP synthase uses this process to create ATP from adenosine diphosphate (ADP) and inorganic phosphate $\left(\mathrm{P}_{\mathrm{i}}\right)$ [6-9].

Previously thought to be only the "powerhouse" of the cell it is now clear that mitochondria are multifaceted. In addition to their role in cellular bioenergetics, mitochondria control reactive oxygen species (ROS) levels and calcium homeostasis, and biosynthesize macromolecules including lipids, amino acids and nucleotides [10]. Furthermore, mitochondria are involved in many cellular original author(s) and the source, provide a link to the Creative Commons licence, and indicate if changes were made. The images or other third party material in this article are included in the article's Creative Commons licence, unless indicated otherwise in a credit line to the material. If material is not included in the article's Creative Commons licence and your intended use is not permitted by statutory regulation or exceeds the permitted use, you will need to obtain permission directly from the copyright holder. To view a copy of this licence, visit http://creativecommons.org/licenses/by/4.0/. The Creative Commons Public Domain Dedication waiver (http://creativeco mmons.org/publicdomain/zero/1.0/) applies to the data made available in this article, unless otherwise stated in a credit line to the data. 
physiological processes, including cell fate, differentiation, proliferation and apoptosis [11, 12]. Alongside its more established roles, mitochondria are key regulators of the innate and adaptive immune system. Immune cells undergo significant cell-type specific metabolic changes during an immune response, moving from a quiescent to an active state that requires significant metabolites from mitochondria $[13,14]$. Mitochondria can regulate immunity via metabolic pathways, inducing transcriptional changes, activating inflammation, mitochondrial dynamics (fission and fusion) and endoplasmic reticulum signalling $[14,15]$.

Mitochondrial stress, either driven by the environment, pathogenesis or ageing, leads to a myriad of dysregulation that can cause both neurodegeneration and neuroinflammation. Mitochondria are vital in regulating cellular adaption to stressors, including impaired biogenesis, mitochondrial DNA (mtDNA) damage, ageing, nutrient restriction and aberrant imbalances between fission and fusion events. If left unchecked, these processes can cause damage to nucleic acids, lipids and proteins through ROS, resulting in sustained oxidative stress [16, 17]. Oxidative stress modulates mitochondrial dynamics through posttranscriptional modifications, including ubiquitination [18]. This, in turn, leads to a build-up of damaged mitochondria and ultimately causes cell death and broader tissue dysfunction. In particular, tissues with high energy demands such as the heart, muscles, brain and retina are susceptible to mitochondrial dysfunction [19]. To mitigate the effects of stressors, several control mechanisms can be activated contributing to mitochondrial homeostasis [17].

Mitochondria first-line defence mechanisms including enzymatic (such as superoxide dismutase, the peroxiredoxin/thioredoxin system and the glutathione peroxidase/reductase system) and non-enzymatic (such as GSH, vitamins E, A and C) antioxidants contribute to the maintenance of redox homeostasis [20]. However, beyond the utilization of antioxidants there exists several mitochondrial quality control mechanisms. These include regulation of mitochondrial fission and fusion events, which facilitate segregation of damaged mitochondria and axonal transport of mitochondria (fission) and the exchange of materials needed for their repair, such as mtDNA (fusion) [16, 21]. The mitochondrial unfolded protein response system, a mitochondria-to-nucleus transduction pathway, which promotes mitochondrial and cellular function if mitochondrial damage is sensed [22]. The ubiquitin-proteasome system leads to degradation of damaged outer mitochondrial membrane (OMM) proteins, and proteases lead to the removal of inner mitochondrial membrane (IMM) and mitochondrial matrix proteins [23]. Lastly, the export of damaged proteins via mitochondrial-derived vesicles (MDVs) or selective removal of damaged mitochondria via mitophagy end with their degradation in lysosomes [24].

PTEN-induced kinase 1 (PINK1) and Parkin RBR E3 ubiquitin-protein ligase (PARKIN) signalling play a key role in mitophagy and mitochondrial motility and size. PINK1 accumulates at the OMM in response to a reduction in mitochondrial $\Delta \Psi \mathrm{m}$ caused by damage/dysfunction. In turn, this recruits PARKIN from the cytosol to the OMM were its E3 activity promotes mitophagy, through ubiquitination of mitochondrial proteins, leading to mitochondrial degradation. Defective mitophagy and PINK1/PARKIN signalling are present in neurodegenerative diseases including Alzheimer's disease (AD), Parkinson's disease (PD) and glaucoma [25-30].

Mutations in the PINK1/PARKIN signalling pathway disrupts the sensitive homeostatic and quality control processes conducted by mitochondria. Mutations in PINK1 and PARKIN are localised throughout their genes affecting all their protein domains (Fig. 1). PINK1 and PARKIN mutations are responsible for more than $50 \%$ of the autosomal recessive juvenile parkinsonism (ARJP) cases [31]. However, there are several other causative genes for PD linked to mitochondrial dysregulation, including LRRK2, DJ1, ATP13A2 and SCNA, in addition to other PD risk genes [32-45]. Furthermore, dysregulation of PINK1/PARKIN signalling has been associated with amyotrophic lateral sclerosis (ALS) and Huntington's disease (HD), as well as eye diseases, such as agerelated macular degeneration (AMD), and is associated with retinal degeneration [46-51]. Efforts for the amelioration of mitochondrial dysfunction through lentiviral and adeno-associated viral (AAV) mediated PINK1 and PARKIN gene augmentation therapeutics show promise (Table 1).

\section{Main text PINK1/PARKIN signalling}

The mitochondrial serine/threonine-protein kinase PINK1, also known as BRPK and PARK6, protects cells from mitochondrial stress-induced dysfunction. Localized to chromosome 1 in position 1p36.12, the PINK1 gene has 8 exons encoding a 581 amino acid protein. It contains an N-terminal mitochondrial targeting sequence (MTS), a transmembrane domain (TM), a $\mathrm{N}$-terminal regulatory domain (NT), a conserved protein kinase domain comprising of a N-lobe and C-lobe, and lastly a C-terminal domain (CTD) (Fig. 1a). PARKIN, also known as PDJ, AR-JP, LPRS2 and PARK2 is localized to chromosome 6 in position $6 \mathrm{q} 26[61,62]$. PARKIN gene has 14 exons encoding a 465 amino acid protein which is comprised of an $\mathrm{N}$-terminal ubiquitin-like (Ubl) domain and a C-terminal RING1-IBR-RING2 (RBR) domain. 


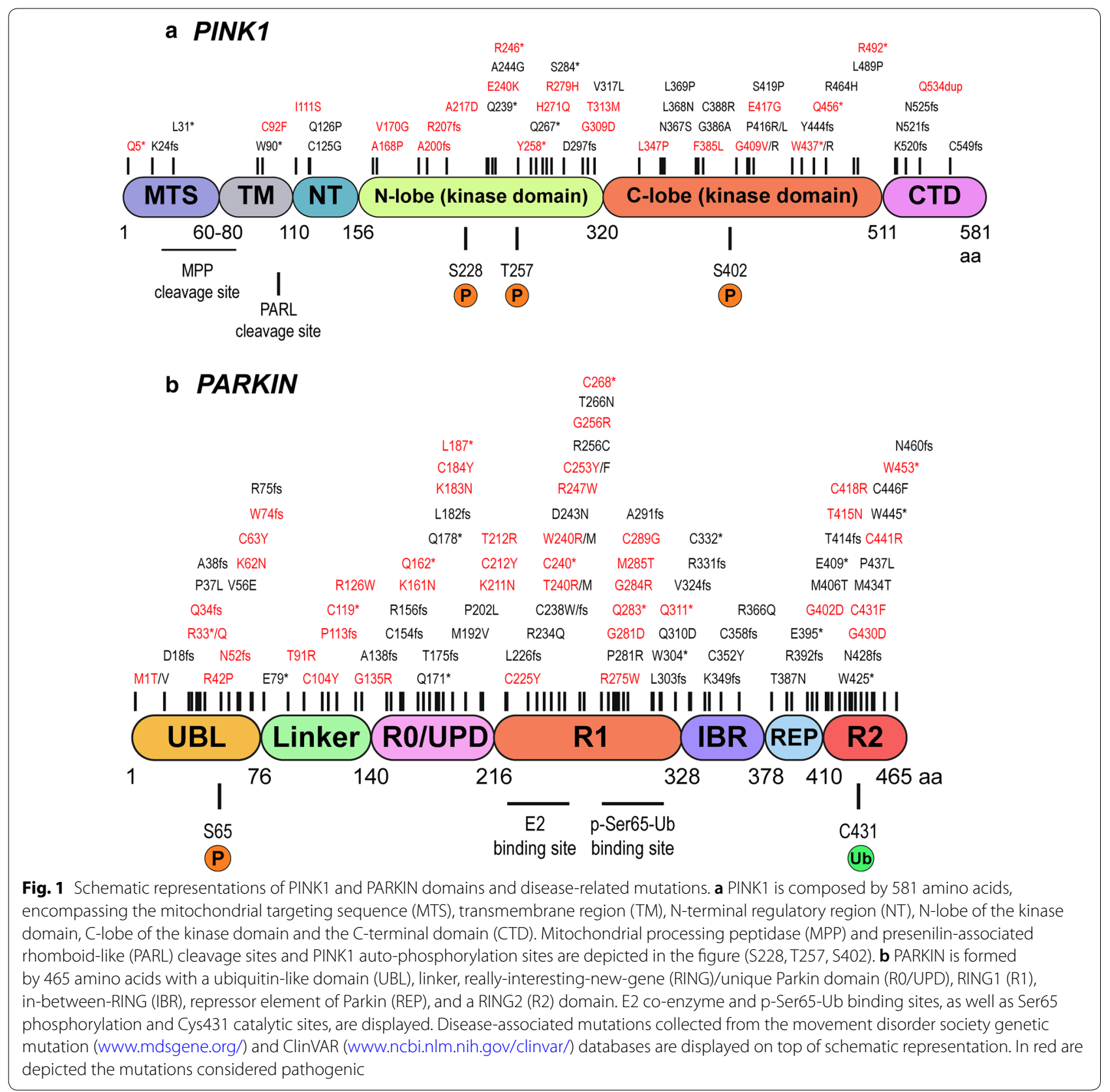

A RING0 domain sits N-terminally adjacent to RING1 and residing between the in-between-RING (IBR), and RING2 domains is a Repressor Element of Parkin (REP) motif (Fig. 1b) [63-66]. Under healthy conditions, mitochondria have an optimal, relatively high $\Delta \Psi \mathrm{m}$ and will import, process and lead to the degradation of PINK1 (Fig. 2). However, under unhealthy conditions like oxidative stress, low $\Delta \Psi \mathrm{m}$ causes PINK1 mitochondrial accumulation leading to PARKIN recruitment from the cytoplasm and initiation of autophagic degradation of the damaged mitochondria, the mitophagy pathway (Fig. 3)
[67-70]. This pathway is governed by phosphorylation and ubiquitination, posttranscriptional modifications mediated by PINK1 and PARKIN, respectively.

The tightly regulated import to and subsequent proteolysis of PINK1 in the mitochondria leads to its processing from the full length $63 \mathrm{kDa}$ protein precursor to the mitochondrial processing peptidase (MPP)-processed $60 \mathrm{kDa}$ intermediated, to its final presenilins-associated rhomboid-like protein (PARL)-processed $52 \mathrm{kDa}$ "mature" form (Fig. 2a, b) [71-73]. The translocase of the outer membrane (TOM) and of the inner membrane 
Table 1 Summary of the PARKIN and PINK1 gene augmentation viral vectors

\begin{tabular}{|c|c|c|c|c|c|c|c|c|c|}
\hline Viruses & $\begin{array}{l}\text { Capsid } \\
\text { serotype }\end{array}$ & Promoter & Sequence & $\begin{array}{l}\text { Injection } \\
\text { place }\end{array}$ & $\begin{array}{l}\text { Volume } \\
\text { injected }\end{array}$ & Dose & $\begin{array}{l}\text { Disease } \\
\text { model }\end{array}$ & Animal & References \\
\hline Lentivirus & $\begin{array}{l}\text { HIV-1 based } \\
\text { vector } \\
\text { with VSVG } \\
\text { envelops }\end{array}$ & PGK & Rat Parkin & S.N. & $2.5 \mu \mathrm{l}$ & $\begin{array}{l}3.6 \times 10^{8} \mathrm{pg} \\
\text { of p24 per } \\
\mathrm{ml}\end{array}$ & $\begin{array}{l}\text { a-synuclein } \\
\text { rat model } \\
\text { for PD }\end{array}$ & Wistar rats & {$[52]$} \\
\hline Lentivirus & $\begin{array}{l}\text { HIV-1 based } \\
\text { vector } \\
\text { with VSVG } \\
\text { envelops }\end{array}$ & CMV & $\begin{array}{l}\text { Human } \\
\text { PARKIN }\end{array}$ & S.N. & $2 \mu l$ & $\begin{array}{l}10^{8} \mathrm{pg} \text { of p24 } \\
\text { per ml }\end{array}$ & $\begin{array}{l}\text { 6-Hydroxy- } \\
\text { dopamine } \\
\text { rat model } \\
\text { for PD }\end{array}$ & Rats & [53] \\
\hline AAV & $2 / 2$ & CBA & $\begin{array}{l}\text { HA-tagged- } \\
\text { PARKIN }\end{array}$ & S.N. & $2 \mu \mathrm{l}$ & $\begin{array}{l}3.6 \times 10^{12} \mathrm{vg} / \\
\mathrm{ml}\end{array}$ & $\begin{array}{l}\text { MPTP-treated } \\
\text { mice, a } \\
\text { model for } \\
\text { sporadic PD }\end{array}$ & C57BL/6 mice & {$[54]$} \\
\hline AAV & $2 / 2$ and $2 / 5$ & CMV/CBA & $\begin{array}{l}\text { Human } \\
\text { PARKIN }\end{array}$ & S.N. & $2 \times 2 \mu \mathrm{l}$ & $\begin{array}{l}2.6 \times 10^{12} \mathrm{vg} / \\
\mathrm{ml}\end{array}$ & $\begin{array}{l}\text { 6-Hydroxy- } \\
\text { dopamine } \\
\text { rat model } \\
\text { for PD }\end{array}$ & Rats & [55] \\
\hline AAV & $2 / 2$ & $\mathrm{CMV} / \mathrm{CBA}$ & $\begin{array}{l}\text { Human } \\
\text { PARKIN }\end{array}$ & S.N. & $4 \mu \mathrm{l}$ & $5 \times 10^{12} \mathrm{vg} / \mathrm{ml}$ & $\begin{array}{l}\text { Tau-induced } \\
\text { dopamin- } \\
\text { ergic degen- } \\
\text { eration rat } \\
\text { model for } \\
\text { PD }\end{array}$ & $\begin{array}{l}\text { Sprague-- } \\
\text { Dawley rats }\end{array}$ & {$[56]$} \\
\hline AAV & $2 / 6$ & PGK & Rat Parkin & S.N. & $2 \mu \mathrm{l}$ & $\begin{array}{c}4.7 \times 10^{10} \\
\text { TUs } / \mathrm{ml}\end{array}$ & $\begin{array}{l}\text { Metham- } \\
\text { phetamine } \\
\text { induced } \\
\text { neurotoxic- } \\
\text { ity rat model } \\
\text { for PD }\end{array}$ & $\begin{array}{l}\text { Sprague-- } \\
\text { Dawley rats }\end{array}$ & [57] \\
\hline AAV & $2 / 8$ & CMV & $\begin{array}{l}\text { Human } \\
\text { PARKIN }\end{array}$ & S.N. & $\begin{array}{l}2 \mu \mathrm{l} \text { in mice } \\
3 \mu \mathrm{l} \text { in rats }\end{array}$ & $\begin{array}{l}2.0 \times 10^{11} \mathrm{vg} / \\
\mathrm{ml}\end{array}$ & $\begin{array}{l}\text { T240R-PARKIN } \\
\text { induced } \\
\text { dopa- } \\
\text { minergic } \\
\text { degenera- } \\
\text { tion model } \\
\text { for PD }\end{array}$ & $\begin{array}{l}\text { C57BL/6 J } \\
\text { mice Wistar } \\
\text { rats }\end{array}$ & {$[58]$} \\
\hline AAV & $2 / 2$ & CMV & Rat Parkin & Vitreous & $5 \mu \mathrm{l}$ & $\begin{array}{l}1.0 \times 10^{13} \mathrm{vg} / \\
\mathrm{ml}\end{array}$ & $\begin{array}{l}\text { Chronic } \\
\text { hyper- } \\
\text { tensive } \\
\text { glaucoma } \\
\text { model }\end{array}$ & $\begin{array}{l}\text { Sprague-- } \\
\text { Dawley rats }\end{array}$ & {$[30]$} \\
\hline AAV & $2 / 1$ & CMV & $\begin{array}{l}\text { Human } \\
\text { PARKIN }\end{array}$ & Striatum & $\begin{array}{l}3 \mu \mathrm{l} \text { in rats } \\
5 \times 10 \mu \mathrm{l} \text { in } \\
\text { monkeys }\end{array}$ & $\begin{array}{l}7.0 \times 10^{12} \mathrm{vg} / \\
\mathrm{ml}\end{array}$ & $\begin{array}{l}\text { a-synuclein } \\
\text { rat model } \\
\text { for PD }\end{array}$ & $\begin{array}{l}\text { Sprague- } \\
\text { Dawley rats } \\
\text { Macaque } \\
\text { monkeys }\end{array}$ & [59] \\
\hline AAV & $2 / 2$ & CMV & Human PINK1 & Hippocampus & $2 \mu \mathrm{l}$ & $\begin{array}{l}5.0 \times 10^{12} \mathrm{vg} / \\
\mathrm{ml}\end{array}$ & $\begin{array}{l}\text { mAPP mouse } \\
\text { model for } \\
\text { AD }\end{array}$ & mice & {$[60]$} \\
\hline
\end{tabular}

AAV Adeno-associated virus, CBA hybrid cytomegalovirus immediate/early enhancer-chicken $\beta$-actin, $C M V$ cytomegalovirus, $P G K$ phosphoglycerate kinase, S.N. substantia nigra, TU transducing units, Vg viral genomes, VSVG vesicular stomatitis virus

(TIM)23 complexes facilitate the importation of the PINK1 precursor via interaction with its MTS to the IMM. At the IMM, PINK1 undergoes cleavage at Ala103 by the protease PARL in a $\Delta \Psi \mathrm{m}$ dependent manner. Under normal, healthy conditions PINK1 is imported and processed for degradation. In contrast, if $\Delta \Psi \mathrm{m}$ dissipates, PINK1 remains localized to the OMM and is unable to be processed by PARL [72, 74]. Upon cleavage,
PINK1 returns to the cytosol to be degraded by the ubiquitin-proteasome system by UBR1, UBR2 and UBR4 through the $\mathrm{N}$-end rule pathway, leading to low levels of PINK1 (Fig. 2a, b) [75]. Recently Sekine et al. [76] found some PD related PINK1 mutations, I111S, C125G and Q126P, affecting an evolutionary conserved negatively charged amino acid cluster motif that constitutes the C-terminal of the PINK1 TM, can still be imported even 


\section{a Healthy}

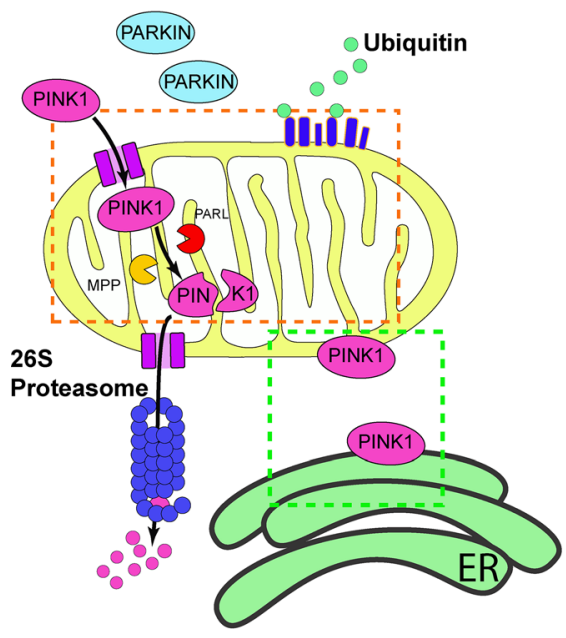

Ubiquitin

OMM substrates

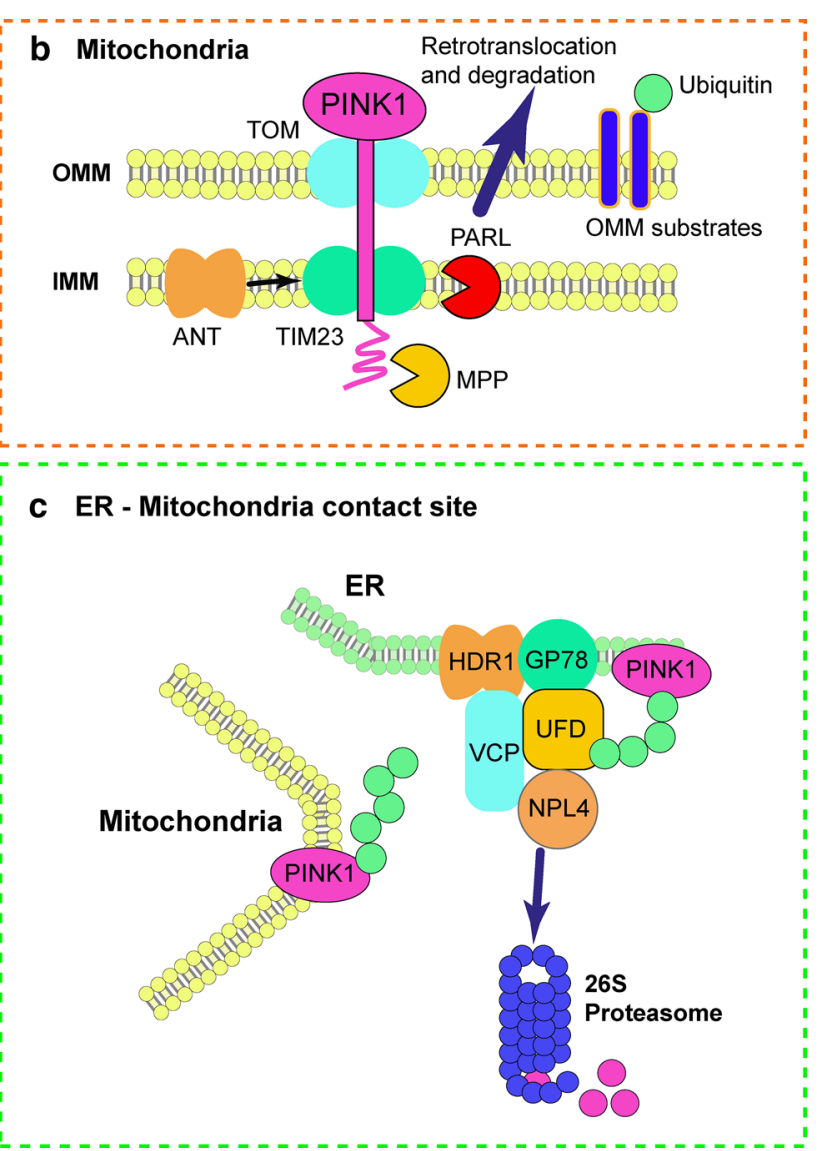

Fig. 2 The canonical PINK1/PARKIN pathway. $\mathbf{a}$ and $\mathbf{b}$ In healthy mitochondria, PINK1 is constitutively imported via translocase of the outer membrane (TOM)/translocase of the inner membrane (TIM)23 complexes to the inner mitochondrial membrane (IMM), cleaved by two proteases (mitochondrial processing peptidase (MPP) and presenilin-associated rhomboid-like (PARL)) and retro-translocated to the cytosol. Cleaved PINK1 is then degraded by the ubiquitin/proteasome system. While Parkin remains inactive in the cytosol. (a and c) PINK1 is also present at the mitochondria-endoplasmic reticulum (ER) interface, where it interacts with the endoplasmic-reticulum-associated protein degradation (ERAD) machinery. At the ER, PINK1 degradation by the proteasome is controlled by the ERAD E3 ubiquitin ligases HRD1 and gp78 and by the ERAD-associated proteins VCP, UFD1, andUFD2A

if $\triangle \Psi \mathrm{m}$ dissipates. These mutants were found not to be cleaved by PARL but by the protease OMA1 at the IMM, suggesting that PINK1 did not accumulate on the damaged mitochondria's OMM for initiation of mitophagy. However, these PINK1 mutants could lead to PARKIN recruitment under OMA1 suppression.

In contradiction to the degradation of the $52 \mathrm{kDa}$ PINK1 by the N-end rule pathway is the finding by the Przedborski Lab that ubiquitinated PINK1 is mostly anchored to the OMM and not in the cytosol. Importantly, they identified that the $\mathrm{N}$-terminal phenylalanine forming a proposed N-degron motif of PINK1 was not facing the cytosol but rather located inside the OMM, suggesting PINK1's low mitochondrial levels are due to continuous ubiquitination and proteasomal degradation under healthy conditions [73]. Recently, the same team identified the mechanism by which PINK1 content is kept at low levels. They found that upon PARL-processing the $52 \mathrm{kDa}$ PINK1 localizes at the mitochondrialendoplasmic reticulum interface and can interact with ER-associated degradation pathway E3 ligases Gp78 and HRD1 (Fig. 2c). These facilitate PINK1's ubiquitination allowing valosin containing proteins, UFD1 and UFD2A, to target PINK1 for proteasomal degradation [77]. Other proteases such as matrix-AAA and caseinolytic mitochondrial matrix peptidase (ClpXP) can cleave PINK1. These may coordinate with PARL to govern the stability and localization of PINK1 [71, 75]. In damaged mitochondria, TOM does not import PINK1, and it remains uncleaved at the OMM, where it undergoes dimerization and autophosphorylation (Fig. 3) [78, 79]. Interestingly, Sekine et al. [76] found that without the TOM complex 


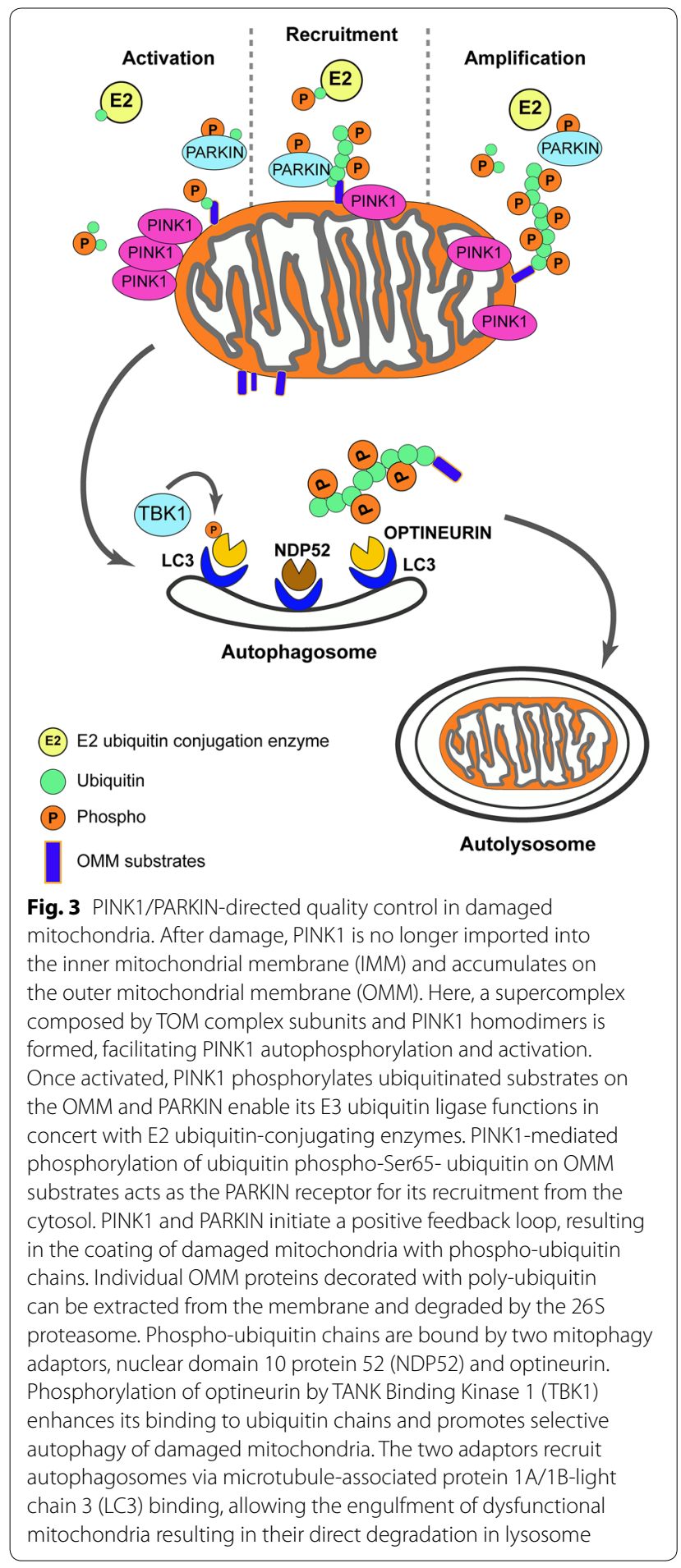

accessory member Tom7 PINK1 was imported to depolarised mitochondria. Tom7 appears crucial in PINK1 OMM accumulation and also plays a role in PINK1 kinase activation for PARKIN recruitment. Phosphoglycerate mutase family member 5 (PGAM5) also binds PINK1 and is required for mitochondrial stabilisation of full-length PINK1 on the OMM upon mitochondrial depolarisation, preventing its cleavage by PARL at the IMM [80].

Under basal conditions, three factors have been identified which show that PARKIN's protein-folding maintains PARKIN in an autoinhibited state: (1) inaccessibility of the E2-binding site on RING1 due to its occlusion by the REP domain [65]; (2) a conserved cysteine residue on RING2 (Cys431) is made inaccessible by RING0 [64, 65, 81]; (3) the Ubl domain inhibits parkin activity through the interface with RING1 and IBR domains [82-85]. The protein folding of PARKIN thus prevents the binding of Ub containing E2s to RING1 and the subsequent thiolbased transfer of Ub to the RING2 cysteine residue. The Cys431 residue is catalytic, being required for the ligase activity of PARKIN. The catalytic residue allows for the formation of an isopeptide bond between $\mathrm{Ub}$ and the lysine residue of the protein $[64,65,86]$.

PINK1 is upstream of PARKIN and through the Ub/ Ubl switch leads to activation of PARKIN by their phosphorylation at residue Ser65 (Fig. 3) [83, 84, 87-93]. Phosphorylation of Ubl increases PARKIN's affinity for pUb. The binding of pUb to PARKIN enhances the rate at which PARKIN itself is phosphorylated by PINK1 [94, 95]. Specific phosphorylation of either Ub or Ubl leads to PARKIN activation; concomitant phosphorylation, however, leads to enhanced PARKIN activation [91, 92, 94]. Binding of pUb to PARKIN's Ubl domain is essential for remodelling of and exposure of RING1 to the binding of the Ub containing E2s and is in line with previous computational analysis [83, 96, 97]. Ubl phosphorylation or binding of pUb to Ubl has also been shown to lead to local rearrangement of the IBR and its decreased affinity for the Ubl domain, revealing cryptic binding sites in a region called the Ubiquitin Binding Region (UBR) [85]. Three surface areas, UBR1, 2 and 3, that could interact with Ub were explored. Both UBR2 and UBR3 were needed for PARKIN activity. The IBR rearrangement in active PARKIN allows binding of Ub containing E2s to the binding site on RING1 while its Ub creates a bridge to the IBR of a neighbouring PARKIN molecule [85]. This association allows for the utilization of the RING2 catalytic domain of neighbouring PARKIN molecules [85]. In summary, pUb is important for dissociation and phosphorylation of PARKIN's Ubl domain allowing its recruitment to the mitochondria. Subsequent PINK1 activation of PARKIN through Ser65 phosphorylation in the Ubl facilitates binding of E2 enzymes leading to PARKIN's ligase activity. Several mutations exist throughout PARKIN, affecting its activity and stability (Fig. 1b) [98-100].

If there is severe mitochondrial dysfunction the amplified phospho-ubiquitin chains on the OMM signal the recruitment of autophagy adaptors such as nuclear dot 
protein 52 (NDP52) and Optineurin (OPTN). In turn, NDP52 and OPTN lead to the recruitment and activation of tank binding kinase 1 (TBK1), activated TBK1 phosphorylates OPTN stabilizing its binding at the phospho-ubiquitin chains [101]. Interestingly, PINK1/ PARKIN-dependent mitophagy-induced sequestration of TBK1 leads to its removal from its physiological role at the centrosome causing G2/M cell cycle arrest. This highlights a possible role of PINK1/PARKINs in mitochondrial quality control before cell division takes place, preventing "unfit" mitochondria being passed on to daughter cells [102]. OPTN and NDP52 along with other autophagy adaptors lead to the recruitment of microtubule-associated proteins $1 \mathrm{~A} / 1 \mathrm{~B}$ light chain 3 (LC3), which engage with the autophagosome. Migration and subsequent fusion of the autophagosome with the lysosome, which is modulated by the RAS-related GTP-binding ( $\mathrm{Rab}$ ) proteins, creates the autolysosome where the mitochondrial proteins are degraded and processed for recycling (Fig. 3). Initiation of autophagy has been found in the absence of LC3 via the Unc-51 like kinase 1 (ULK1) complex, which is comprised of ULK1, FAK family kinase-interacting protein of $200 \mathrm{kDa}$ (FIP200), autophagy related gene (ATG)12 and ATG101 [103]. The ULK1 complex, which mediates autophagy in a nutrient-dependent manner, is recruited to ubiquinated cargo independently of AMPK by the cooperation of NDP52, and TBK1 [103]. Recently, Nozawa et al. [104] found that TBC1 domain family member 9 (TBC1D9), which is recruited to mitochondria via $\mathrm{Ca}_{2}^{+}$-dependent Ub-binding, is essential for the activation and recruitment of TBK1 and therefore the subsequent recruitment of NDP52 and the ULK1 complex to damaged mitochondria.

\section{PINK1/PARKIN in neurodegeneration}

Neurodegeneration corresponds to any pathological conditions, primarily affecting neurons [105]. Typically, neurodegenerative diseases are progressive disorders that lead to neuronal degeneration and cell death. The umbrella term "neurodegenerative diseases" includes conditions such as AD, PD, amyotrophic lateral sclerosis (ALS), Huntington's disease (HD) and also eye diseases, such as age-related macular degeneration (AMD), glaucoma and a subset of inherited retinal dystrophies. Ageing is considered a primary risk factor in most neurodegenerative diseases [106]. Mitophagy increases in muscles and neurons during ageing but disruption of PINK1/ PARKIN signalling abolishes this increase, hindering this crucial quality control mechanism and thus allowing the accumulation of harmful mitochondria [107111]. Imbalances in mitochondrial fission and fusion are important for neuronal dynamics and are affected in neurodegeneration being linked to programmed cell death pathways [112]. PINK1 and PARKIN are essential in these processes interacting with fission/fusion machinery molecules such as fission protein Drp1 (dynaminrelated protein 1) and fusion protein OPA1 (optical atrophy 1). Overexpression of Pink1 or Parkin in rat hippocampal neurons leads to increased fission and can suppress a mitochondrial elongation phenotype caused by $\operatorname{Drp} 1$ knockdown. A similar phenotype is caused by PINK1 inactivation, leading to increased fusion. Yu et al. [113] found that in dopaminergic neurons, similarly to hippocampal neurons, PINK1/PARKIN had a comparable influence on mitochondrial dynamics with tipping the fission/fusion balance towards more fission.

Alzheimer's disease, the most common cause of dementia in the elderly, is a progressive neurodegenerative disease leading to memory deficits and cognitive decline, which in turn lead to behavioural and speech impairments. Ageing is the predominant risk factor with a prevalence of $10 \%$ for individuals over the age of 65 [114]. Pathologically, AD is hallmarked by the presence of amyloid plaques, mainly consisting of agglomerated amyloid- $\beta(A \beta)$ peptides, and neurofibrillary tangles, mostly consisting of hyperphosphorylated tau, which are associated to cellular degeneration [115]. Another prominent hallmark of $\mathrm{AD}$ is the accumulation of dysfunctional mitochondria [116]. Robust induction of PARKIN-mediated mitophagy is found in human patients' brains and in a human amyloid precursor protein (hAPP) transgenic mouse model of AD [28]. During disease progression, cytosolic PARKIN levels are reduced, leading to increased mitochondrial dysfunction [28]. Mitochondria from $\mathrm{AD}$ patients skin fibroblasts exhibited slower recovery of $\Delta \Psi \mathrm{m}$ after insult [27]. Dysregulated protein levels of PARKIN and PINK1 were found in AD fibroblasts and brain biopsies. In both AD fibroblasts and hippocampal brain biopsies from Braak II-III stage patients, full length and cleaved PINK1 were increased. However, while PARKIN was diminished in the AD fibroblasts, it was found upregulated in Braak VI stage hippocampal brain biopsies. In AD fibroblasts, PARKIN recruitment after mitochondria depolarisation was found to be reduced, indicating defective mitophagy due to insufficient tagging of damaged mitochondria. Overexpression of PARKIN could compensate for the defective mitophagy in the AD fibroblasts [27]. Familial cases of AD are linked to autosomal dominant mutations of presenilin 1 (PSEN1). Both PSEN1 and PSEN2 are involved in a molecular cascade that modulates mitophagy via their control of PINK1 transcription and function. Goiran et al. found that PARKIN upregulates PSEN1 promoter activation. In turn, control of $\gamma$-secretase activity, by PSEN1, targets APP leading to its fragmentation, yielding $A \beta$ and the APP 
intracellular domain (AICD). Interaction of forkhead box O3a (FOXO3a) with AICD initiates Pink1 transcription and AICD-mediated control of autophagic processes, which were found to be PINK1 dependent. As PINK1 recruits PARKIN to damaged mitochondria this highlights a feedback loop between the two genes that may become disrupted in neurodegenerative conditions [117, 118].

Parkinson's disease is a movement disorder attributed to the loss of dopaminergic neurons in the substantia nigra. Motor symptoms include resting tremor, rigidity and bradykinesias, while non-motor symptoms include autonomic dysfunction, anxiety and sleeping problems. PINK1 and PARKIN are mutated in some forms of familial PD $[119,120]$. Pink1 and Parkin null Drosophila have learning and memory abnormalities and weakened circadian rhythms, in addition to underlying electrophysiological irregularities in clock neurons [121]. Late-stage PD patients can develop dementia with an accumulation of $\alpha$-synuclein in Lewy bodies $[41,59,122,123]$. Nitrosative stress is a key pathological hallmark in PD and aging. Nitric oxide-induced S-nitrosylation of PARKIN and PINK1 leads to compromised mitophagy and thus accumulation of damaged mitochondria [124-126]. One of the major causes of early-onset PD is due to loss-offunction mutations in genes including glucocerebrosidase (GBA), RAB39B, DJ-1, PINK1 and PARKIN [25, 26, 127-130]. Pink1 and Parkin KO mice show minimal signs of neurodegeneration but still provide valuable insights into possible mechanisms of action [131-135]. Parkin KO mice have an increase in extracellular dopamine concentration in the striatum, there is reduction in synaptic excitability in spiny neurons and dysfunction of the nigrostriatal pathway [131]. Another mouse model, presenting inactivated PARKIN due to a exon 3 deletion causing a premature stop codon, showed cognitive and motor deficits with inhibition of both amphetamineinduced dopamine release and glutamate neurotransmission [133]. Additionally, some mouse and rat Parkin $\mathrm{KO}$ models exhibit no neurodegeneration or any detectable neurochemical or pathological changes compared to wild type counterparts $[135,136]$. This may be due to developmental compensation for PARKIN in these models. Due to the lack of neurodegeneration found in mouse KO Parkin models, Stephenson et al. [137] tried a novel approach by creating a double $\mathrm{KO}$ of Parkin and Parkin co-regulated gene (PACRG). Parkin and PACRG share a bidirectional promoter, with the transcriptional start sites being approximately $200 \mathrm{bp}$ apart. However, no abnormalities of the dopaminergic system in the substantia nigra and no loss of neurons were found.

Analysis of PARKIN and its substrates has yielded possible PD associated neurodegenerative mechanisms.
PARKIN mediates the ubiquitination and proteasomedependent degradation of synaptotagmin-11 (Syt11) under normal conditions [138]. Syt11 is a novel risk gene involved in PD whose accumulation in dopaminergic neurons due to PARKIN dysfunction inhibits endocytosis and hence dopamine release leading to neurotoxicity [40, 138]. Interestingly, Wang et al. [138] found that knockdown of Syt11 in Parkin knockdown background lead to the recovery of the dopamine release in the substantia nigra. PARKIN also mediates the ubiquitination and proteasome-dependent degradation of Zinc finger protein 746 (ZNF746, also known as PARIS) under normal conditions [139]. Accumulation of ZNF76 occurs due to PARKIN inactivation and is present in PD human brain samples [139, 140]. ZNF746 is a transcriptional repressor of peroxisome proliferator-activated receptor-gamma (PPAR $\gamma$ ) coactivator- $1 \alpha$ (PGC- $1 \alpha)$ expression and its target gene nuclear respiratory factor 1 (NRF-1). In Parkin $\mathrm{KO}$ animals, dopaminergic neurons loss was found to be in a ZNF746-dependent manner with its overexpression leading to dopaminergic neuronal loss in the substantia nigra [139]. Recently, Brahmachari et al. [140] found that ZNF746 is a pivotal mediator of $\alpha$-synuclein induced neurodegeneration affecting both dopaminergic and non-dopaminergic neurons. In $\alpha$-synuclein overexpression mouse models c-Abl kinase phosphorylation of PARKIN led to the impairment of its activity and subsequent accumulation of ZNF746. Importantly, they found that ablation of ZNF746 leads to the rescue of the neurodegenerative phenotype observed in $\alpha$-synuclein models of familial and sporadic PD [140]. PARKIN inactivation also leads to the accumulation of another one of its substrates, aminoacyl-tRNA synthetase complex interacting multifunctional protein-2 (AIMP2), found to be increased in Parkin KO mouse models and PD brain samples [140-143]. AIMP2 overexpression causes a progressive and degenerative loss of dopaminergic neurons due to Poly(ADP-ribose) polymerase-1 (PARP1) over activation. PARP1 inhibition in the AIMP2 overexpressed mouse model was protective and prevented degeneration of dopaminergic neurons [141].

Outside its role as an E3 ubiquitin ligase involved in mitophagy, PARKIN also has a role in transcriptional regulation (reviewed by Costa et al. [144]). As an example, PARKIN has been found to undergo nuclear translocation upon DNA damage where it may play a role in the transcriptional control of DNA repair mechanisms such as base and nucleotide excision repair and double strand break repair [145]. The transcription factor role of PARKIN therefore may act as a cellular defense mechanism against genotoxicity and suggests that DNA damage plays a pathogenic role in neurodegenerative disease such as PD [144, 145]. Recently, Shires et al. [146] have 
identified a role for nuclear PARKIN during hypoxia in activation of estrogen-related receptor $\alpha(E R R \alpha)$, which is a transcription factor associated with mitochondrial metabolism and biogenesis. Interestingly, they also found that PARKIN mutants, ParkinR42P and ParkinG430D, are excluded from the nucleus and therefore unable to induce the transcription factor role of PARKIN. Therefore, the transcriptional roles as well as the mitophagic roles of PARKIN should be considered in PD as well as other neurodegenerative conditions. A Pink1 KO mouse model in which the pathogenic patient mutation G309D was inserted into exon 5 presented mitochondrial dysfunction leading to defects in ATP generation along with a reduction in dopamine in the nigrostriatal projection with a concurrent reduction in locomotor activity, but again without neurodegeneration [132]. Generation of a further Pink1 KO mouse, where exons 4-7 were deleted and consequently the majority of the kinase domain was removed, creating a nonsense mutation, caused impairment of dopamine release with striatal plasticity reduction. These impairments were rescued either in the presence of dopamine receptor agonists or due to stimulation of dopamine release, again highlighting the relevance of the nigrostriatal circuit [134]. In the same Pink1 KO mouse model, it was shown that relocation of PARKIN to mitochondria induced by a collapse of $\Delta \psi \mathrm{m}$ relies on PINK1 expression [147]. In another Pink1 KO mouse model, where exon 2 to exon 5 were replaced with a LacZ/Neo cassette, impaired dopamine release was also found. As compared to wild-type, dopamine from striatal slices of Pink1 KO mice decreased in an age-dependent manner. Additionally, it was found an age-dependent decrease in basal oxygen consumption rates and ATP levels in Pink1 KO mice, which suggests that decreased ATP generation may be the cause of the decreased dopamine release [148]. Recently, silencing of Pink1 in cultured mouse hippocampal neurons caused a decrease in postsynaptic density proteins PSD95 and Shank as well as glutamate receptor subunit NR2B and mGluR5. Interestingly, the authors found changes in actin regulatory proteins RhoGAP29 and ROCK2 which were concurrent with changes in spine morphology. The changes in dendritic spines, showing increased thin density spines and reduced head size of stubby spines, may be a sign of presymptomatic changes that lead to neurodegeneration in PD [149]. In comparison, a Pink1 KO rat model showed nigral neurodegeneration with $50 \%$ dopaminergic cell loss, an increase in striatal dopamine and serotonin content and significant motor deficits [136].

The inability of rodent models to recapitulate the severe neurodegeneration seen in PD patients may be due to low levels of PINK1, as has been identified in mice [150]. These studies also suggest there may be PINK1 independent mitophagy pathways yet to be eluded too. Recently, CRISPR/Cas9-mediated Pink1 deletion in rhesus macaques triggered severe neurodegeneration of the cortex, striatum and substantia nigra, with several newborns dying shortly after birth $[151,152]$. These data suggest that in humans full PINK1 loss may lead to lethality in early development. Interestingly, a KO mouse model of the PINK1 OMM stabilisation protein PGAM5 leads to a more severe PD-like animal model than in Pink1 KO mouse models. The Pgam5 KO mice show a significant degeneration in dopaminergic neurons in addition to a PD-like movement disorder characterised by gait changes and bradykinesia [80].

Lastly, in light of mitochondria's role in the immune system, we should look to reassess the many disorders associated with defective mitochondrial genes in terms of potential autoimmunity. PD, as one example, has been recently hotly debated as also being an autoimmune disease [153-158]. PINK1 and PARKIN have been found to regulate adaptive immunity, being key for mitochondrial antigen presentation in a mitophagy independent process. This process instead relies on the generation of MDVs with a direct correlation between the extent of MDV formation and the amount of mitochondrial antigen presentation. PINK1 and PARKIN inhibit this process, the presence of PARKIN was found to be key in preventing $\mathrm{Snx} 9$ being recruited to mitochondria and initiating MDV formation [159]. Further supporting this notion, it was recently found that intestinal infection of Pink1 KO mice with Gram-negative bacteria elicited mitochondrial antigen presentation and autoimmune mechanisms. These responses triggered mitochondrial-specific $\mathrm{CD}^{+}{ }^{+} \mathrm{T}$-cells that were found to induce dopaminergic neuron death. The infected Pink1 KO mice presented acute motor symptoms [153]. Therapeutics that influence mitochondrial immune regulation will be an exciting area to be developed in treating these diseases.

Amyotrophic lateral sclerosis is a progressive and debilitating neuromuscular disease marked by degeneration of motor neurons in the brain and spinal cord, leading to muscle atrophy, paralysis and to death $3-5$ years after disease onset. Mitochondrial dysfunction has been associated with ALS, with causative genes including autophagy adaptors OPTN and SQSTM1, and autophagy enhancer TBK1 [160-163]. Altered expression levels of mRNA and protein for PINK1 have been identified in human ALS patients muscle [164]. Mutations in superoxide dismutase 1 (SOD1) gene are associated with familial ALS [165]. A SOD1 ${ }^{\text {G93A }}$ ALS mouse model exhibits dysregulated PINK1 and PARKIN and progressive defects in mitochondrial function and dynamics [47, 164]. In spinal cord motor neurons of the SOD $1^{\mathrm{G} 93 \mathrm{~A}}$ mouse model 
increased mitophagy, as marked by a mitochondrial accumulation of OPTN and SQSTM1, was found, while there was a depletion of PARKIN and mitochondrial dynamic and biogenesis proteins. Interestingly, Parkin overexpression in NSC34 motor neuron-like cells, in which human G93A mutant SOD1 was expressed, was found to exacerbate the effects of mitochondrial damage leading to increased cell toxicity. However, Parkin knockout (KO) in $\mathrm{SOD} 1^{\mathrm{G} 93 \mathrm{~A}}$ mice led to delayed disease progression with slower motor neuron loss and muscle denervation. Thus, chronic PARKIN expression in ALS may lead to sustained activation of mitochondrial quality control leading to a depletion of mitochondrial dynamic-related proteins and inhibition of mitochondrial biogenesis, and these alterations ultimately lead to progressive mitochondrial dysfunction [47].

A hallmark of ALS is the accumulation of transactive response DNA-binding protein $43 \mathrm{kDa}$ (TDP-43) at ubiquitin-positive inclusions, and these TDP-43 protein inclusions have reduced PARKIN protein levels [166, 167]. PINK1 and PARKIN are differentially misregulated at the RNA and protein levels in animal models of TDP-43 proteinopathy. These models showed a decrease in Parkin mRNA and protein levels upon overexpression of TDP-43 but not PINK1. TDP-43 was found to govern Parkin mRNA levels in both an intron-mediated and intron-independent manner. While TDP-43 did not regulate Pink1 at the RNA level, its overexpression led to the cytosolic accumulation of cleaved PINK1 due to the impairment of the ubiquitin-proteasome system [46]. In stress conditions, such as ageing, this accumulation of cleaved PINK1 leading to reduced mitochondrial activity may be a risk factor promoting neurodegeneration. Lastly, Sun et al. [46] found that by ameliorating the misregulation of PINK1 or PARKIN by their down or up-regulation, respectively, leads to suppression of the degenerative phenotypes observed in a TDP-43 proteinopathy fly model.

Huntington's disease is a fatal autosomal dominant disorder caused by misfolding and aggregation of the huntingtin (HTT) protein due to expansion of a polyglutamine tract (CAG repeats) within its $\mathrm{N}$-terminal domain. The disease leads to cognitive deficits, choreatic movements and psychiatric disturbances [168, 169]. The mutant HTT protein has been found to negatively affect the initiation of autophagy/mitophagy through interfering with the formation and stability of the ULK1 and PtdIns3K complexes, which are essential for autophagosome formation [170]. Mitochondrial fragmentation is a hallmark of HD patients with mutant HTT found to abnormally interact with fission protein Drp1 [171-174]. Additionally, swollen/degenerated mitochondria have been identified in a HD knock-in pig model which exhibited selective degeneration of striatal medium spiny neurons [175]. Furthermore, HD patients have impairment in the mitochondrial respiratory chain $[176,177]$. In a Drosophila model of HD, mutant HTT led to mitochondrial fragmentation in photoreceptors, being abnormally ring-shaped. However, PINK1 overexpression enhanced mitochondrial quality control in a PARKIN-dependent manner, alleviating the formation of the ring-shaped mitochondria. Additionally, they found that PINK1 neuroprotection in the Drosophila brain led to normalization of ATP levels, improved neuronal integrity and increased cell survival. Lastly, Khalil et al. [48] found that defective mitophagy found in striatal cells from a HD knock-in mouse could be partially restored upon PINK1 overexpression.

Age-related macular degeneration is a complex retinal disorder and the leading cause of severe blindness in the elderly population, resulting from both environmental and genetic risk factors [178-180]. AMD affects central vision and its pathobiology includes activation of the innate immune response, neovascularisation, oxidative stress and a build-up of proteins and lipids [179, 181]. Accumulation of mtDNA damage is associated with AMD progression [182]. In the RPE of a Nuclear factor erythroid 2-related factor 2 (NFE2L2/NRF2) and peroxisome proliferator-activated receptor-gamma captivator 1 -alpha $(P G C-1 \alpha)$ double knockout (dKO) dry AMD-like mouse model, elevated levels of oxidative stress markers, damaged mitochondria, accumulated lysosomal lipofuscin and extracellular drusen-like deposits were found. Nrf2 is part of the Keap1-Nrf2 pathway which is important in oxidative stress regulation, and PGC- $1 \alpha$ is involved in mitochondrial biogenesis and in the antioxidant defence system [183]. Recently, in the same NRF2/PGC-1 $\alpha$ $\mathrm{dKO}$ mouse model at 1 year of age, dysregulation of mitophagy was evaluated. Compared to wild type RPE a significant increase in PINK1 and PARKIN levels on damaged mitochondria was found in the $\mathrm{dKO}$, this additionally corresponded to an increase in the number of autophagosomes with mitochondrial cargo. However, despite elevated mitophagy initiation this model seemed to have uncompleted degradation of mitochondrial cargo via an unclarified dysfunction in the autolysosomes [49]. Mitophagy may be a novel therapeutic target for the amelioration of AMD. In a Drosophila model of calcium cytotoxicity in which active TRPP ${ }^{365}$ channels lead to retinal degeneration, abnormalities in mitochondrial morphology and function were found in photoreceptors. Interestingly, overexpression of both PINK1 and PARKIN prevented the TRPP ${ }^{365}$-induced photoreceptor cell degeneration [51]. Moreover, in a PINK1/PARKIN-induced photoreceptor degeneration 
model, the induction of cell death by PINK1/PARKIN was found to be independent of mitophagy [50].

Glaucoma, caused by progressive degeneration of retinal ganglion cells, leads to severe and irreversible blindness, with 111.8 million people predicted to be affected by $2040[184,185]$. Elevated intraocular pressure (IOP) is considered a major risk factor for glaucoma [186]. Therapies directed at lowering IOP have proved to be successful at preserving vision in some glaucoma patients, but this does not work for all patients [187]. Glutamate excitotoxicity, a pathophysiological mechanism in glaucomatous neurodegeneration, leads to changes in mitochondrial dynamics, causing their dysfunction and cell death [188]. Overexpression of Parkin protects retinal ganglion cells from glutamate excitotoxicity [189]. Furthermore, in a chronic hypertensive glaucoma rat model, overexpression of Parkin was protective, partially restoring mitophagy and improving mitochondrial health [30]. Recently, Chernyshova et al. [190] explored the role of glaucoma specific OPTN gene mutations and their effect on PARKIN-dependent mitophagy using mitophagy impaired HeLa cells. OPTN is a receptor for PARKINmediated mitophagy pathway, and mutations of OPTN cause primary open-angle glaucoma (POAG) [29, 191]. Interestingly, Chernyshova et al. [190] observed that while two ALS OPTN mutant proteins failed to rescue the impaired HeLa cells, seven glaucoma specific OPTN mutations did restore mitophagy and localized correctly to mitochondria. This work suggests that OPTN gene mutation in glaucoma may be mitophagy independent.

\section{PINK1 and PARKIN in neuroinflammation}

Neurodegeneration and neuroinflammation are concurrent processes in many disorders. Neuroinflammation is a process that involves the synthesis and release of pro-inflammatory mediators, such as cytokines and chemokines, and infiltration of immune cells that if uncontrolled contribute to neurodegeneration exacerbation. Here, we summarize the supporting pieces of evidence for the involvement of PINK1 and PARKIN in neuroinflammation.

As discussed before, mutations in PARKIN and PINK1 cause early-onset PD [25, 192]. Primary human bloodderived macrophages obtained from PD patients with PARKIN mutations display high levels of NLRP3 and IL-1 $\beta$ when stimulated with lipopolysaccharide (LPS)nigericin or LPS-ATP [193]. PINK1G309D, the loss-offunction mutation associated with early-onset familial PD, promotes the expression of VCAM-1 and exacerbates the attachment of monocytes to brain endothelial cells [129]. Humans with monoallelic and biallelic PARKIN mutations display elevated serum levels of IL-6, IL-1 $\beta$, CCL2 and CCL4, whereas the levels of these molecules in serum of PINK1 heterozygotes were similar to those in control serum [194]. In contrast, mice lacking either Pink1 or Parkin have no substantial PD-relevant phenotypes, and their levels of cytokines in the serum is unaltered [131, 134, 135, 194]. However, acutely prepared cortical slices from Pink1 knockout mice, presented elevated levels of pro-inflammatory cytokines, such as TNF$\alpha$, IL-1 $\beta$, and IL-6 [195]. In mature zebrafish systemic administration of LPS results in increased Pink1 gene expression in the brain [196].

In mice lacking Parkin or Pink1 upon both acute (exhaustive exercise-induced) or chronic (mtDNA mutation-induced) mitochondrial stress, a robust inflammatory phenotype is observed [194]. Following exhaustive exercise, Pink $1^{+/-}$mice show increased IL-6, IFN $\beta 1$, IL-12(p70), CXCL1 and CCL4, whereas Parkin ${ }^{+/-}$mice display increased IL-6. Mice expressing a proofreadingdefective mtDNA polymerase (mutator mice) accumulate mutations in mtDNA but do not exhibit neurodegeneration or elevated cytokines [194, 197]. However, PARKINdeficient mutator mice presented elevated IL-6, IFN $\beta 1$, TNF $\alpha$, IL-1 $\beta$, CCL2, IL-12(p70), IL-13, IL-17, CXCL1 and CCL4 [194]. Inflammation derived from either exhaustive exercise or mtDNA mutation results from the activation of the stimulator of interferon genes (STING), a central regulator of the type I interferon response to cytosolic DNA, and not due to activation of NRLP3 [194] (Fig. 4). Interestingly, PARKIN-deficient mutator mice exhibit dopaminergic neuron loss and motor impairment that can be rescued by treatment with levodopa [109] and, as well, by loss of STING, by crossing PARKIN-deficient mutator mice with STING-null mice (goldenticket mice) [194]. STING is activated when double-stranded DNA binds cyclic guanosine monophosphate (GMP) - adenosine monophosphate (AMP) synthase (cGAS), which in turn generates cyclic GMP-AMP (cGAMP) [198]. PARKIN-deficient mice subjected to acute or chronic mitochondrial stress displayed both increased mtDNA copy number and ratio of mitochondrial to nuclear DNA in the serum; this increase is not rescued by loss of STING [194]. STING activation by binding of cGAS to cytosolic double-stranded DNA (dsDNA), including mtDNA, and STING-mediated inflammation resulting from an accumulation of mtDNA mutations in mutator mice, indicate that mtDNA is a crucial inflammatory signal in the absence of PARKIN [194]. Release of mtDNA into the cytosol, subsequent interaction of mtDNA with cGAS, and induction of IFN $\beta$ expression is also observed in mouse models of macular degeneration [199] and upon herpes virus infection [200]. Surprisingly, Whitworth and colleagues showed that knockdown of Sting or its downstream effector Relish using RNAi (in vivo), is insufficient to suppress the locomotor deficits or mitochondrial 


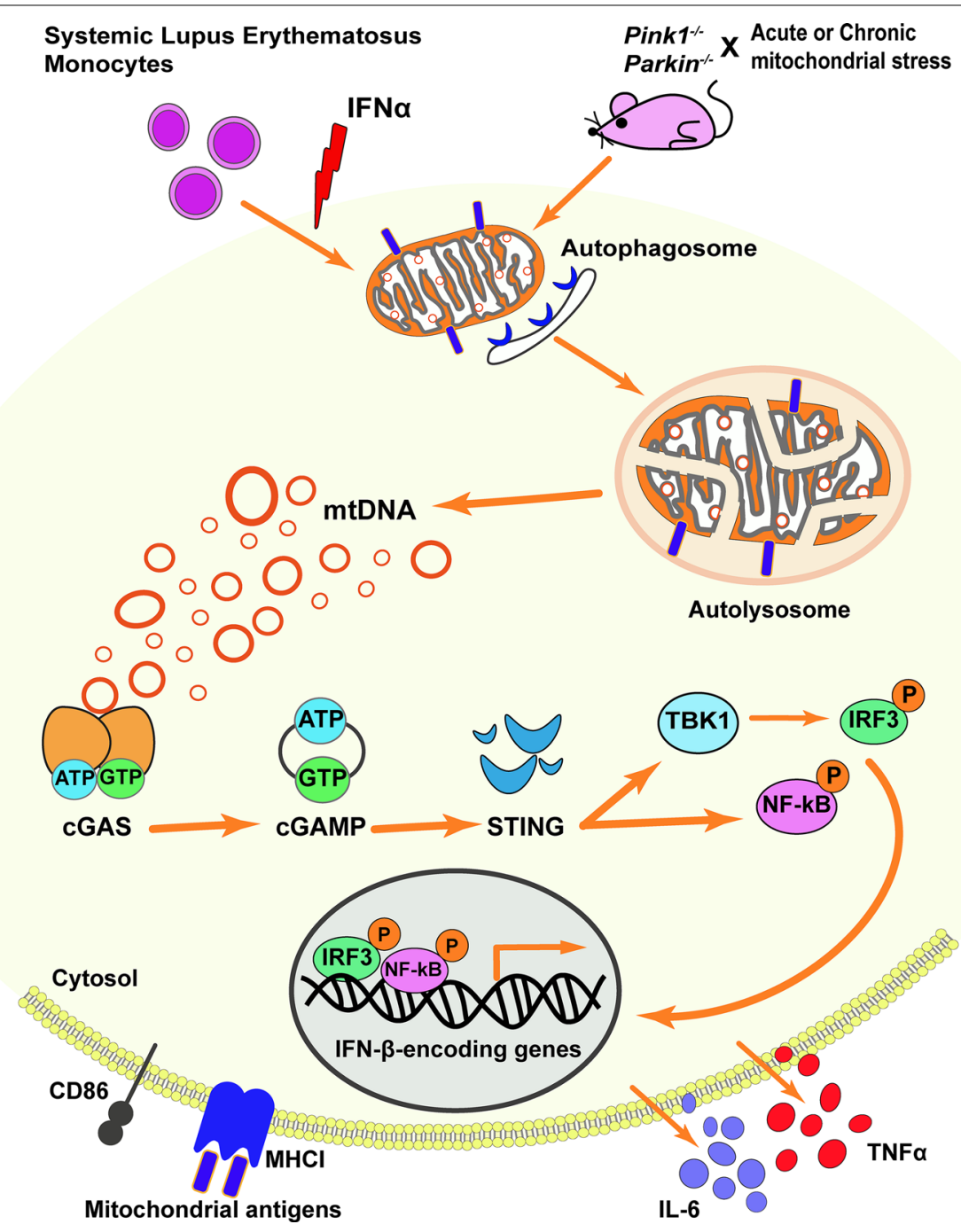

Fig. 4 PINK1/PARKIN-signalling and inflammation. Mice lacking Parkin or Pink1 upon acute (exhaustive exercise-induced) or chronic (mitochondrial DNA (mtDNA) mutation-induced) mitochondrial stress present inflammation due to the activation of the stimulator of interferon genes (STING) as result from the accumulation of mtDNA mutations and release of mtDNA into the cytosol. While, in systemic lupus erythematosus excessive IFNa damages mitochondrial respiration, leading to oxidative stress that impairs lysosomal degradation and obstructs autophagic clearance. Undegraded mtDNA from mitochondria, interact with the cytosolic DNA sensor CGAS in a sequence-independent way, promoting a conformational change of cGAS to catalyse the formation of 2,3-cyclic GMP-AMP (cGAMP). The cGAS activation, as well as cGAMP synthase, activate STING, recruiting binding kinase 1 (TBK1) as well as interferon regulatory factor 3 (IRF3). The IRF3 then displaces to the nucleus and induces immune-stimulated genes and type I IFN expression. The nuclear factor kappa-light-chain-enhancer of activated B cells (NF-kB) signalling can also be activated by STING. In the absence of PARKIN and PINK1, high levels of mitochondrial antigens are presented to major histocompatibility complex (MHC) class I molecules in macrophages and dendritic cells triggering an adaptive immune response

disruption in Pink1 or Parkin Drosophila mutants [201]. Furthermore, Sting loss does not affect the behavioural phenotypes associated with a Drosophila mtDNA mutator model, nor the combined effect of mtDNA mutations in a Parkin background, concluding that phenotypes associated with loss of Pink1/Parkin are not universally due to aberrant activation of the Sting pathway [201]. Not only dysregulation of mitochondrial function promotes inflammation, but also inflammation itself leads to mitochondrial dysfunction suggesting the existent of a pro-inflammatory loop with mitochondria playing a central role. IFN $\alpha$-mediated deregulation of mitochondrial metabolism, including mitochondria hyperpolarization and upregulation of PINK1, and impairment of autophagic degradation, results in cytosolic accumulation of mtDNA passible of being sensed via STING to promote further inflammation [202] (Fig. 4). Parkin knockout mice submitted to chronic LPS exposure 
develop fine-locomotor deficits and loss of nigral dopaminergic neurons. However, in these mice, neuroinflammatory responses in the midbrain are similar to the ones observed in wild-type mice [203].

In the absence of PARKIN and PINK1, high levels of mitochondrial antigens are presented by major histocompatibility complex (MHC) class I molecules in both macrophages and dendritic cells through mitochondrial-derived vesicles triggering adaptive immune response [159]. Therefore, PINK1 and PARKIN seem to repress mitochondrial antigen presentation providing a link between mitochondrial dynamics and the potential engagement of autoimmune mechanisms in the aetiology of PD [159].

The expression of PINK1 and PARKIN is increased in reactive astrocytes in the diseased human brain [204, 205], suggesting that these proteins affect or regulate gliadependent immune responses. Lack of PINK1 increases glia-mediated primary neuron apoptosis and nitric oxide (NO)-dependent neuroblastoma cell death [206], suggesting that PINK1 in glial cells promotes a neuronal protective effect. Ablation of PINK1 differentially affects inflammation-induced gene expression and NO production in astrocytes, microglia and mixed astrocytes/microglia [206]. PINK1-deficient astrocytes show proliferation defects, increased p38MAPK activation [207], elevated NO production, impaired mitochondrial function and increased cytoplasmatic and mitochondrial ROS levels [206]. PINK1-deficient astrocytes exposure to LPS and IFNY overexpress inducible nitric oxide synthase (iNOS), $\mathrm{NO}$ and TGF $\beta 1$. However, PINK1-deficient microglia only show decreased IL-10 secretion [206]. In vitro, LPSactivated murine microglia cell line (BV2) with reduced levels of PARKIN show increased levels of TNF $\alpha$, IL-1 $\beta$, IL-6 and iNOS mRNA via NF- $\mathrm{kB}$ and activating protein 1 (AP-1). Quite similar pro-inflammatory profile, with an increase of TNF- $\alpha$, IL-1 $\beta$, IL-6, IL- 18, monocyte chemoattractant protein-1 (MCP-1) and NRLP3 is also observed in Parkin-null primary microglia cells exposed to LPS [193]. Mouse microglia primary cultures, with reduced levels of PARKIN, present a similar increase in TNF $\alpha$, IL- 6 and iNOS and a decrease in IL-1 $\beta$, after exposure to either IFN $\gamma$, TNF $\alpha$ or both [208]. These data suggest that PINK1 or PARKIN loss exacerbates inflammation and promotes survival of activated microglia, contributing to neuroinflammation. Furthermore, in macrophages, PARKIN suppresses LPS-induced expression of TNF $\alpha$, IL-6 or MCP-1 production [209, 210].

\section{PARKIN and PINK1 gene augmentation therapy for neurodegenerative disorders}

In the previous sections, we summarized the importance of PINK1 and PARKIN in controlling critical cellular mechanisms. The extensive published data pinpoint that disruption of PINK1/PARKIN signalling culminates in impaired mitochondrial function and ultimately contribute to neurodegenerative and neuroinflammatory processes. Thus, PARKIN and PINK1 gene augmentation therapy seems, at least in theory, a promising strategy for brain and retinal degenerative disorders. Table 1 summarizes the viral vectors used in each study.

Pre-clinical studies show that PARKIN gene augmentation ameliorates disease features in several disease models [30, 52-59]. Amongst the different gene augmentation therapy vectors, lentiviral $[52,53]$ and adeno-associated viral (AAV) vectors have been described [30, 54-59]. Lentiviral-mediated gene therapy delivery of Parkin into substantia nigra significantly reduces $\alpha$-synuclein-induced neuropathology, including preservation of tyrosine hydroxylase-positive cell bodies in the substantia nigra and sparing of tyrosine hydroxylase-positive nerve terminals in the striatum [52]. Moreover, overexpression of human PARKIN in rat's substantia nigra prevented 6-hydroxydopamineinduced degeneration of dopaminergic terminals and cell bodies and ameliorated the motor behaviour [53]. In the recent years, AAV vectors have become popular gene delivery tools due to their safety profile, low immunogenicity, lack of toxicity and to the fact of the AAV genomes do not integrate into the host genome [211]. Moreover, the existence of several natural AAV serotypes and derivatives that differ in their tropism, makes AAV a powerful tool for gene delivery in the central nervous system. Several AAV serotypes including 2, 5, 6 and 8 have been used to transduce neurons and deliver Parkin under the control of the cytomegalovirus (CMV), CMV enhancer/chicken $\beta$-actin or phosphoglycerate kinase 1 (PGK) promoter $[30,54,55$, 57, 58]. As observed for lentiviral gene therapy vectors, AAV-mediated delivery of Parkin into the substantia nigra also demonstrated to improve disease features in different PD animal models. The therapeutic potential of AAV-gene transfer of Parkin on the dopaminergic system was assessed on 1-methyl-4- phenyl-1,2,3,6tetrahydropyridine (MPTP)-treated mice, a model for PD [54]. AAV2/2-Parkin treatment resulted in a higher survival rate of dopamine neurons in the substantia nigra. Protection at the neuronal level was supported by increased amphetamine-induced contralateral turning behaviour, a test to evaluate presynaptic neurotransmission, once amphetamine inhibits the dopamine transporter and stimulates dopamine release from presynaptic axon terminals [54]. Another study tested the effects of AAV2/5-Parkin delivery before a 4-site striatal 6-hydroxydopamine lesion [55]. Parkin treated lesioned rats displayed $67 \%$ in amphetamine-induced 
rotational behaviour reduction and used their affected paw nearly twice as often as control rats in the cylinder test, demonstrating a clear motor improvement after treatment [55]. After neuropathological analysis of the lesioned rats, no differences in surviving nigral dopaminergic neurons or striatal dopaminergic innervation was observed. Therefore, the authors hypothesize that the behavioural improvement resulted from enhanced levels of tyrosine hydroxylase due to Parkin overexpression. To test this, the effects of nigral human PARKIN overexpression in intact rats was examined. The human PARKIN treated striatum contained more dopamine, suggesting that PARKIN enhances nigral dopaminergic neurotransmission rather than exerting any protective effect on the nigrostriatal tract [55]. Increase in PARKIN levels attenuates methamphetamine-induced decreases in striatal tyrosine hydroxylase immunoreactivity in a dose-dependent manner, indicating that PARKIN exerts a neuroprotective effect on striatal dopaminergic terminals upon methamphetamine neurotoxicity [57]. High dosage of methamphetamine causes selective degeneration of dopaminergic terminals in the striatum, sparing other striatal terminals and cell bodies [57]. The overexpression of AAV-mediated $\alpha$-synuclein decreases the density of dopaminergic axon terminals in the striatum of rats and monkeys, which is ameliorated by co-expression of PARKIN [59]. Moreover, AAV-delivery of Parkin is associated with either less accumulation of $\alpha$-synuclein protein, phosphorylation at serine residue at $129^{\text {th }}$ position or both [59]. AAV-mediated-tau overexpression induced dopaminergic neuron loss, and PARKIN prevented the loss of substantia nigra dopaminergic neurons in tauinduced dopaminergic degeneration model [56]. Studies performed in young transgenic mice overexpressing Parkin, specifically in neurons, show improved MPTPinduced mitochondrial impairment in the substantia nigra, while old transgenic mice present decreased striatal $\alpha$-synuclein [212]. Also, pharmacological strategies exploit PARKIN signalling activation have been tested. Inhibition of ROCK promotes increased recruitment of HK2, a positive regulator of PARKIN, to mitochondria, leading to increased targeting of mitochondria to lysosomes and removal of damaged mitochondria from cells. Furthermore, ROCK inhibitors have neuroprotective effects in a fly PD model [213]. A sign of warning came from the study performed by van Rompuy et al. [58], where administration AAV2/8-CMV-human PARKIN, in (healthy, non-lesioned) wild-type rats substantia nigra induced progressive and dose-dependent dopaminergic cell death, starting from 8 weeks after injection. The authors excluded non-specific cell death induced by an inflammatory response due to the vector preparations. Interestingly, administration of the same vector and dose in mouse substantia nigra did not cause toxicity [58]. The evidence gathered seems to support the use of PARKIN viral delivery for the treatment of PD. However, most of these studies were performed in acute and induced disease models, where treatment is often provided before the injury. To the best of our knowledge, there is no direct evidence of functional rescue via viral-mediated delivery of Parkin in a Parkin-deficient animal. Moreover, although some of these studies show behavioural improvements and dopaminergic neuronal survival, very little is described about the mechanism underlying these observations. The concerns raised by van Rompuy et al. [58] suggest the necessity of performing toxicity assays to study the potential deleterious effect of long term overexpression of PARKIN, especially in human-derived tissues.

Overexpression of PARKIN has been also exploited as a treatment for AD. In fact, overexpression of Parkin ameliorates impaired mitophagy and promotes the removal of damaged mitochondria in amyloid $\beta$-treated cells, indicating that upregulation of PARKIN-mediated mitophagy may be a potential strategy also to treat $\mathrm{AD}$ [214]. However, not only PARKIN gene therapy vectors have been developed and tested. In the literature, there is at least one study assessing the potential of PINK1 gene augmentation as a treatment for $\mathrm{AD}$. The rationale for that originates from the fact that in the brains of patients with AD and transgenic AD mice model PINK1 is downregulated [60]. AAV-PINK1 transduction significantly reduced human amyloid- $\beta$ levels by $65-70 \%$ in the hippocampus of transgenic mAPP mice that overexpress a human mutant form of APPbearing both the Swedish (K670N/M671L) and the Indiana (V717F) mutations (APPSwInd) at 11-13 months of age. PINK1 overexpression promotes the clearance of damaged mitochondria by augmenting autophagy signalling via activation of autophagy receptors (OPTN and NDP52), thereby alleviating amyloid- $\beta$-induced loss of synapses and cognitive decline in mAPP mice [60]. Transgenic mice overexpressing the PARKIN in neurons were crossed with APP/PS1 transgenic mice. Overexpression of PARKIN restored activity-dependent synaptic plasticity and rescued behavioural abnormalities. Moreover, overexpression of Parkin was associated with down-regulation of APP protein expression, decreased $\beta$-amyloid load and reduced inflammation [215].

A recent study demonstrated that overexpression of Parkin cDNA driven by a CMV promoter, encapsulated in AAV2/2, and delivered by intravitreal injection, improved the outcome in a rat model of glaucoma. Delivery of Parkin into the retina protected against retinal ganglion cell loss, attenuated glial fibrillary acidic protein 
(GFAP) expression, promoted optineurin expression, improved mitochondrial health, and partially restored dysfunction of mitophagy in chronic hypertensive glaucoma rats [30].

Khalil et al. [48] studied the impact of PINK1 overexpression in a Drosophila model of HD. Their data demonstrate that PINK1 overexpression rescues HD neuronal pathology, ameliorated ATP levels, neuronal integrity and adult fly survival, demonstrating that PINK1 counteracts the neurotoxicity of mutant Huntingtin [48]. PINK1 neuroprotection against mutant Huntingtin is dependent on PARKIN, mitofusin and the voltage-dependent anion channel [48].

\section{Conclusions}

The fast-increasing list of scientific publications related to PINK1/PARKIN signalling demonstrates how limited is our knowledge about this pathway and at the same time how disease-relevant this seems to be. It is becoming clear that PINK1 and PARKIN related processes are capable of modulating neurodegeneration and neuroinflammation, either by removing dysfunctional mitochondria, controlling mtDNA release or promoting neuroprotective and anti-inflammatory phenotypes.

Based on the studies here compiled gene augmentation of PARKIN and PINK1 seems a promising strategy for the treatment of brain and retinal neurodegenerative disorders. All the pre-clinical studies summarized in this review not only increase our knowledge about PINK1/ PARKIN signalling but raise hope for the development of new treatments for neurodegenerative disorders.

\footnotetext{
Abbreviations

$\triangle \Psi \mathrm{m}$ : Mitochondrial membrane potential; AAV: Adeno-associated virus; AD: Alzheimer's disease; ADP: Adenosine diphosphate; AICD: APP intracellular domain; AIMP2: Aminoacyl-tRNA synthetase complex interacting multifunctional protein-2; ALS: Amyotrophic lateral sclerosis; AMD: Age-related macular degeneration; AMP: Adenosine monophosphate; APP: Amyloid precursor protein; ARJP: Autosomal recessive juvenile parkinsonism; ATG12: Autophagy related gene 12; ATG101: Autophagy related gene 101; ATP: Adenosine triphosphate; Cl-V: Protein complexes (I-V); cGAMP: Cyclic guanosine monophosphate-adenosine monophosphate; cGAS: Cyclic guanosine monophosphate-adenosine monophosphate synthase; ClpXP: Caseinolytic mitochondrial matrix peptidase; CMV: Cytomegalovirus; CTD: C-terminal domain; dKO: Double knockout; Drp1: Dynamin-related protein 1; dsDNA: Double-stranded DNA; ERRa: Estrogen-related receptor a; ETC: Electron transport chain; FIP200: FAK family kinase-interacting protein of $200 \mathrm{kDa}$; GBA: Genes including glucocerebrosidase; GFAP: Glial fibrillary acidic protein; GMP: Guanosine monophosphate; HD: Huntington's disease; HTT: Huntingtin; IBR: In-between-RING; IMM: Inner mitochondrial membrane; IOP: Intraocular pressure; iNOS: Inducible nitric oxide synthase; KO: Knockout; LC3: Microtubule-associated protein 1A/1B-light chain 3; LPS: Lipopolysaccharide; MCP-1: Monocyte chemoattractant protein-1; MDV: Mitochondrial derived vesicles; MHC: Major histocompatibility complex; OMM: Outer mitochondrial membrane; MPP: Mitochondrial processing peptidase; MPTP: 1-methyl-4- phenyl1,2,3,6-tetrahydropyridine; mtDNA: Mitochondrial DNA; MTS: Mitochondrial targeting sequence; NDP52: Nuclear dot protein 52; NFE2L2: Nuclear Factor, Erythroid 2 Like 2; NO: Nitric oxide; NRF-1: Nuclear respiratory factor-1; NT:
}

N-terminal regulatory domain; OPA1: Optical atrophy-1; OPTN: Optineurin; OXPHOS: Oxidative phosphorylation; PACRG: Parkin co-regulated gene; PARL: Presenilins-associated rhomboid-like protein; PARKIN: Parkin RBR E3 ubiquitin protein ligase; PARP1: Poly(ADP-ribose) polymerase-1; PD: Parkinson's disease; PGAM5: Phosphoglycerate mutase family member 5; PGC-1a: Proliferatoractivated receptor gamma coactivator-1a; PGK: Phosphoglycerate kinase 1; Pi: Inorganic phosphate; PINK1: PTEN-induced kinase 1; PKD: Protein kinase domain; PPARY: Proliferator-activated receptor gamma; Ptdlns3K: Phosphatidylinositol 3-kinase; PSEN1: Presenilin 1; PSEN2: Presenilin 2; RAB: RAS-related GTP-binding; RBR: RING1-IBR-RING2; REP: Repressor element of Parkin; ROS: Reactive oxygen species; SOD1: Superoxide dismutase 1; STING: Stimulator of interferon genes; Syt 11: Synaptotagmin-11; TBC1D9: TBC1 domain family member 9; TBK1: TANK Binding Kinase 1; TIM: Translocase of the inner membrane; TM: Transmembrane domain; TOM: Translocase of the outer membrane; TDP-43: Transactive response DNA-binding protein 43 kDa; Ubl: Ubiquitin-like; UBR: Ubiquitin binding region; ULK1: Unc-51 like kinase 1; ZNF746: Zinc finger protein 746 .

\section{Acknowledgements \\ PMJQ would like to thank his supportive team members at JCVC.}

\section{Authors' contribution}

PMJQ and CHA wrote the manuscript. PIM and AFA revised the manuscript. PMJQ and CHA conceptualized the figures. CHA designed the figures. All authors read and approved the final manuscript.

\section{Funding}

Foundation for Science and Technology (FCT), Portugal [Strategic Projects: UIDB/04539/2020 and UIDP/04539/2020 (Center for Innovative Biomedicine and Biotechnology) to AFA; and CEECIND/00886/2017 to CHA]. PMJQ is funded by the Curing Retinal Blindness Foundation (CRBF) and the Knights Templar Eye Foundation (KTEF). Foundation for Science and Technology (FCT), Portugal [Strategic Projects: UIDB/04539/2020 and UIDP/04539/2020 (Center for Innovative Biomedicine and Biotechnology) to AFA; and CEECIND/00886/2017 to CHA]. The funding bodies had no role in writing the manuscript.

\section{Availability of data and material}

Not applicable.

Compliance with ethical standards

Conflict of interest

The authors declare that they have no conflict of interest.

Ethics approval

Not applicable.

\section{Consent for publication}

Not applicable.

\author{
Author details \\ 1 Jonas Children's Vision Care, and Bernard and Shirlee Brown Glaucoma \\ Laboratory, Columbia Stem Cell Initiative, Departments of Ophthalmology, \\ Pathology and Cell Biology, Institute of Human Nutrition, Vagelos College \\ of Physicians and Surgeons, Columbia University, New York, NY, USA. ${ }^{2}$ Edward \\ S. Harkness Eye Institute, New York-Presbyterian Hospital, New York, NY, USA. \\ ${ }^{3} \mathrm{CNC}$ - Center for Neuroscience and Cell Biology, University of Coimbra, Coim- \\ bra, Portugal. ${ }^{4}$ Center for Innovative Biomedicine and Biotechnology (CIBB), \\ University of Coimbra, Coimbra, Portugal. ${ }^{5}$ Laboratory of Physiology, Faculty \\ of Medicine, University of Coimbra, Coimbra, Portugal. ${ }^{6}$ Coimbra Institute \\ for Clinical and Biomedical Research (iCBR), Faculty of Medicine, University \\ of Coimbra, Coimbra, Portugal. ${ }^{7}$ Association for Innovation and Biomedical \\ Research on Light and Image (AIBILI), Coimbra, Portugal. ${ }^{8}$ Clinical Academic \\ Center of Coimbra (CACC), Coimbra, Portugal.
}

Received: 8 September 2020 Accepted: 17 October 2020

Published online: 09 November 2020 


\section{References}

1. Benda C (1898) Ueber dier Spermatogenese de Verbebraten und höherer Evertebraten, II. Theil: die Histiogenese der Spermien. Arch Anat Physiol Arch Anat Physiol 73:393-398

2. Bernard G, Bellance N, James D, Parrone P, Fernandez H, Letellier T et al (2007) Mitochondrial bioenergetics and structural network organization. J Cell Sci 120(5):838-848

3. Sjostrand FS (1953) Electron microscopy of mitochondria and cytoplasmic double membranes. Nature 171(4340):30-32

4. Palade GE (1953) An electron microscope study of the mitochondrial structure. J Histochem Cytochem 1(4):188-211

5. Cogliati S, Enriquez JA, Scorrano L (2016) Mitochondrial cristae: where beauty meets functionality. Trends Biochem Sci 41(3):261-273

6. Davies KM, Strauss M, Daum B, Kief JH, Osiewacz HD, Rycovska A et al (2011) Macromolecular organization of ATP synthase and complex I in whole mitochondria. Proc Natl Acad Sci U S A. 108(34):14121-14126

7. Rees DM, Leslie AGW, Walker JE (2009) The structure of the membrane extrinsic region of bovine ATP synthase. Proc Natl Acad Sci USA 106(51):21597-21601

8. Boyer PD, Chance B, Ernster L, Mitchell P, Racker E, Slater EC (1977) Oxidative Phosphorylation and Photophosphorylation. Annu Rev Biochem 46(1):955-966

9. Acín-Pérez R, Fernández-Silva P, Peleato ML, Pérez-Martos A, Enriquez JA (2008) Respiratory Active Mitochondrial Supercomplexes. Mol Cell 32(4):529-539

10. Spinelli JB, Haigis MC (2018) The multifaceted contributions of mitochondria to cellular metabolism. Nat Cell Biol 20(7):745-754

11. Vakifahmetoglu-Norberg H, Ouchida AT, Norberg E (2017) The role of mitochondria in metabolism and cell death. Biochem Biophys Res Commun 482(3):426-431

12. Khacho M, Harris R, Slack RS (2019) Mitochondria as central regulators of neural stem cell fate and cognitive function. Nat Rev Neurosci 20(1):34-48

13. Pearce EL, Pearce EJ (2013) Metabolic pathways in immune cell activation and quiescence. Immunity 38(4):633-643

14. Mills EL, Kelly B, O'Neill LAJ (2017) Mitochondria are the powerhouses of immunity. Nat Immunol 18(5):488-498

15. Angajala A, Lim S, Phillips JB, Kim JH, Yates C, You Z et al (2018) Diverse roles of mitochondria in immune responses: novel insights into immuno-metabolism. Front Immunol 9:1605

16. Youle RJ, Van Der Bliek AM (2012) Mitochondrial fission, fusion, and stress. Science 337(6098):1062-1065

17. Pickles S, Vigié P, Youle RJ (2018) Mitophagy and quality control mechanisms in mitochondrial maintenance. Curr Biol 28(4):170-185

18. Wu Y-T, Wu S-B, Lee W-L, Wei Y-H (2010) Mitochondrial respiratory dysfunction-elicited oxidative stress and posttranslational protein modification in mitochondrial diseases. Ann N Y Acad Sci 1201:147-156

19. Wallace DC, Fan W, Procaccio V (2010) Mitochondrial energetics and therapeutics. Annu Rev Pathol 5(1):297-348

20. Franco-lborra S, Vila M, Perier C (2018) Mitochondrial quality control in neurodegenerative diseases: focus on Parkinson's disease and Huntington's disease. Front Neurosci 12:1-25

21. Chen $\mathrm{H}$, Vermulst $M$, Wang YE, Chomyn A, Prolla TA, McCaffery JM et al (2010) Mitochondrial fusion is required for mtdna stability in skeletal muscle and tolerance of mtDNA mutations. Cell 141(2):280-289

22. Shpilka T, Haynes CM (2018) The mitochondrial UPR: mechanisms, physiological functions and implications in ageing. Nat Rev Mol Cell Biol 19(2):109-120

23. Amadoro G, Corsetti V, Florenzano F, Atlante A, Bobba A, Nicolin V et al (2014) Morphological and bioenergetic demands underlying the mitophagy in post-mitotic neurons: the pink-parkin pathway. Front Aging Neurosci 6:1-18

24. Sugiura A, McLelland G, Fon EA, McBride HM (2014) A new pathway for mitochondrial quality control: mitochondrial-derived vesicles. EMBO J 33(19):2142-2156

25. Kitada T, Asakawa S, Hattori N, Matsumine H, Yamamura Y, Minoshima S et al (1998) Mutations in the parkin gene cause autosomal recessive juvenile parkinsonism. Nature 392(6676):605-608

26. Valente EM, Abou-Sleiman PM, Caputo V, Muqit MMK, Harvey K, Gispert S et al (2004) Hereditary early-onset Parkinson's disease caused by mutations in PINK1. Science 304(5674):1158-1160
27. Martín-Maestro P, Gargini R, Perry G, Avila J, García-Escudero V (2016) PARK2 enhancement is able to compensate mitophagy alterations found in sporadic Alzheimer's disease. Hum Mol Genet 25(4):792-806

28. Ye X, Sun X, Starovoytov V, Cai Q (2015) Parkin-mediated mitophagy in mutant hAPP neurons and Alzheimer's disease patient brains. Hum Mol Genet 24(10):2938-2951

29. Rezaie T, Child A, Hitchings R, Brice G, Miller L, Coca-Prados M et al (2002) Adult-onset primary open-angle glaucoma caused by mutations in optineurin. Science 295(5557):1077-1079

30. Dai Y, Hu X, Sun X (2018) Overexpression of parkin protects retinal ganglion cells in experimental glaucoma article. Cell Death Dis 9(2):88

31. Bonifati V, Dekker MCJ, Vanacore N, Fabbrini G, Squitieri F, Marconi R et al (2002) Autosomal recessive early onset parkinsonism is linked to three loci: PARK2, PARK6, and PARK7. Neurol Sci 23:59-60

32. Bonifati V, Rizzu P, Van Baren MJ, Schaap O, Breedveld GJ, Krieger E et al (2003) Mutations in the DJ-1 gene associated with autosomal recessive early-onset parkinsonism. Science 299(5604):256-259

33. Zimprich A, Biskup S, Leitner P, Lichtner P, Farrer M, Lincoln S et al (2004) Mutations in LRRK2 cause autosomal-dominant parkinsonism with pleomorphic pathology. Neuron 44(4):601-607

34. Gusdon AM, Zhu J, Van Houten B, Chu CT (2012) ATP13A2 regulates mitochondrial bioenergetics through macroautophagy. Neurobiol Dis 45(3):962-972

35. Park JS, Koentjoro B, Veivers D, Mackay-Sim A, Sue CM (2014) Parkinson's disease-associated human ATP13A2 (PARK9) deficiency causes zinc dyshomeostasis and mitochondrial dysfunction. Hum Mol Genet 23(11):2802-2815

36. Grassi D, Howard S, Zhou M, Diaz-Perez N, Urban NT, Guerrero-Given D et al (2018) Identification of a highly neurotoxic a-synuclein species inducing mitochondrial damage and mitophagy in Parkinson's disease. Proc Natl Acad Sci U S A. 115(11):2634-2643

37. Hao LY, Giasson BI, Bonini NM (2010) DJ-1 is critical for mitochondrial function and rescues PINK1 loss of function. Proc Natl Acad Sci USA 107(21):9747-9752

38. Di Fonzo A, Rohé CF, Ferreira J, Chien HF, Vacca L, Stocchi F et al (2005) A frequent LRRK2 gene mutation associated with autosomal dominant Parkinson's disease. Lancet 365(9457):412-415

39. Polymeropoulos MH, Lavedan C, Leroy E, Ide SE, Dehejia A, Dutra A et al (1997) Mutation in the a-synuclein gene identified in families with Parkinson's disease. Science 276(5321):2045-2047

40. International Parkinson Disease Genomics Consortium, Nalls MA, Plagnol V, Hernandez DG, Sharma M, Sheerin U-M et al (2011) Imputation of sequence variants for identification of genetic risks for Parkinson's disease: a meta-analysis of genome-wide association studies. Lancet 377(9766):641-649

41. Ramirez A, Heimbach A, Gründemann J, Stiller B, Hampshire D, Cid LP et al (2006) Hereditary parkinsonism with dementia is caused by mutations in ATP13A2, encoding a lysosomal type 5 P-type ATPase. Nat Genet 38(10):1184-1191

42. Wauters F, Cornelissen T, Imberechts D, Martin S, Koentjoro B, Sue C et al (2020) LRRK2 mutations impair depolarization-induced mitophagy through inhibition of mitochondrial accumulation of RAB10. Autophagy 16(2):203-222

43. Bonello F, Hassoun SM, Mouton-Liger F, Shin YS, Muscat A, Tesson C et a (2019) LRRK2 impairs PINK1/Parkin-dependent mitophagy via its kinase activity: pathologic insights into Parkinson's disease. Hum Mol Genet 28(10):1645-1660

44. Thomas KJ, McCoy MK, Blackinton J, Beilina A, van der Brug M, Sandebring $A$ et al (2011) DJ-1 acts in parallel to the PINK1/parkin pathway to control mitochondrial function and autophagy. Hum Mol Genet 20(1):40-50

45. Grünewald A, Arns B, Seibler P, Rakovic A, Münchau A, Ramirez A et al (2012) ATP13A2 mutations impair mitochondrial function in fibroblasts from patients with Kufor-Rakeb syndrome. Neurobiol Aging 33(8):1843. e1-7

46. Sun X, Duan Y, Oin C, Li JC, Duan G, Deng X et al (2018) Distinct multilevel misregulations of Parkin and PINK1 revealed in cell and animal models of TDP-43 proteinopathy. Cell Death Dis 9(10):953

47. Palomo GM, Granatiero V, Kawamata H, Konrad C, Kim M, Arreguin AJ et al (2018) Parkin is a disease modifier in the mutant SOD 1 mouse model of ALS. EMBO Mol Med. 10(10):e8888 
48. Khalil B, El Fissi N, Aouane A, Cabirol-Pol MJ, Rival T, Liévens JC (2015) PINK1-induced mitophagy promotes neuroprotection in Huntington's disease. Cell Death Dis 6(1):e1617

49. Gurubaran IS, Viiri J, Koskela A, Hyttinen JMT, Paterno JJ, Kis G et al (2020) Mitophagy in the retinal pigment epithelium of dry age-related macular degeneration investigated in the NFE2I/2/PGC-1a-/- mouse model. Int J Mol Sci 21(6):1976

50. Zhuang N, Li L, Chen S, Wang T (2016) PINK1-dependent phosphorylation of PINK1 and Parkin is essential for mitochondrial quality control. Cell Death Dis 7(12):1-12

51. Huang Z, Ren S, Jiang Y, Wang T (2016) PINK1 and Parkin cooperatively protect neurons against constitutively active TRP channel-induced retinal degeneration in Drosophila. Cell Death Dis 7(4):e2179-e2211

52. Lo Bianco C, Schneider BL, Bauer M, Sajadi A, Brice A, Iwatsubo T et al (2004) Lentiviral vector delivery of parkin prevents dopaminergic degeneration in an -synuclein rat model of Parkinson's disease. Proc Natl Acad Sci 101(50):17510-17515

53. Vercammen L, Van der Perren A, Vaudano E, Gijsbers R, Debyser Z Van den Haute $C$ et al (2006) Parkin protects against neurotoxicity in the 6-hydroxydopamine rat model for Parkinson's disease. Mol Ther 14(5):716-723

54. Paterna JC, Leng A, Weber E, Feldon J, Büeler H (2007) DJ-1 and parkin modulate dopamine-dependent behavior and inhibit MPTP-induced nigral dopamine neuron loss in mice. Mol Ther 15(4):698-704

55. Manfredsson FP, Burger C, Sullivan LF, Muzyczka N, Lewin AS, Mandel RJ (2007) rAAV-mediated nigral human parkin over-expression partially ameliorates motor deficits via enhanced dopamine neurotransmission in a rat model of Parkinson's disease. Exp Neurol 207(2):289-301

56. Klein RL, Dayton RD, Henderson KM, Petrucelli L (2006) Parkin is protective for substantia nigra dopamine neurons in a tau gene transfer neurodegeneration model. Neurosci Lett 401(1-2):130-135

57. Liu B, Traini R, Killinger B, Schneider B, Moszczynska A (2013) Overexpression of parkin in the rat nigrostriatal dopamine system protects against methamphetamine neurotoxicity. Exp Neurol 247:359-372

58. Van Rompuy AS, Lobbestael E, Van der Perren A, Van den Haute C, Baekelandt V (2014) Long-term overexpression of human wild-type and T240R Mutant Parkin in rat substantia nigra induces progressive dopaminergic neurodegeneration. J Neuropathol Exp Neurol 73(2):159-174

59. Yasuda T, Miyachi S, Kitagawa R, Wada K, Nihira T, Ren YR et al (2007) Neuronal specificity of a-synuclein toxicity and effect of Parkin coexpression in primates. Neuroscience 144(2):743-753

60. Du F, Yu Q, Yan S, Hu G, Lue LF, Walker DG et al (2017) PINK1 signalling rescues amyloid pathology and mitochondrial dysfunction in Alzheimer's disease. Brain 140(12):3233-3251

61. Shimura H, Hattori N, Kubo SI, Mizuno Y, Asakawa S, Minoshima S et al (2000) Familial Parkinson disease gene product, parkin, is a ubiquitinprotein ligase. Nat Genet 25(3):302-305

62. Spratt DE, Walden H, Shaw GS (2014) RBR E3 ubiquitin ligases: new structures, new insights, new questions. Biochem J 458(3):421-437

63. Morett E, Bork P (1999) A novel transactivation domain in parkin. Trends Biochem Sci 24(6):229-231

64. Riley BE, Lougheed JC, Callaway K, Velasquez M, Brecht E, Nguyen L et al (2013) Structure and function of Parkin E3 ubiquitin ligase reveals aspects of RING and HECT ligases. Nat Commun 4:1982

65. Trempe JF, Sauvé V, Grenier K, Seirafi M, Tang MY, Meńade M et al (2013) Structure of parkin reveals mechanisms for ubiquitin ligase activation. Science 340(6139):1451-1455

66. Hristova VA, Beasley SA, Rylett RJ, Shaw GS (2009) Identification of a novel $\mathrm{Zn}^{2+}$-binding domain in the autosomal recessive juvenile Parkinson-related E3 ligase parkin. J Biol Chem 284(22):14978-14986

67. Matsuda N, Sato S, Shiba K, Okatsu K, Saisho K, Gautier CA et al (2010) PINK1 stabilized by mitochondrial depolarization recruits Parkin to damaged mitochondria and activates latent Parkin for mitophagy. J Cell Biol 189(2):211-221

68. Narendra DP, Jin SM, Tanaka A, Suen DF, Gautier CA, Shen J et al (2010) PINK1 is selectively stabilized on impaired mitochondria to activate Parkin. PLoS Biol 8(1):e1000298

69. Narendra D, Tanaka A, Suen DF, Youle RJ (2008) Parkin is recruited selectively to impaired mitochondria and promotes their autophagy. J Cell Biol 183(5):795-803
70. Lazarou M, Sliter DA, Kane LA, Sarraf SA, Wang C, Burman JL et al (2015) The ubiquitin kinase PINK1 recruits autophagy receptors to induce mitophagy. Nature 524(7565):309-314

71. Greene AW, Grenier K, Aguileta MA, Muise S, Farazifard R, Haque ME et al (2012) Mitochondrial processing peptidase regulates PINK1 processing, import and Parkin recruitment. EMBO Rep 13(4):378-385

72. Jin SM, Lazarou M, Wang C, Kane LA, Narendra DP, Youle RJ (2010) Mitochondrial membrane potential regulates PINK1 import and proteolytic destabilization by PARL. J Cell Biol 191(5):933-942

73. Liu Y, Guardia-Laguarta C, Yin J, Erdjument-Bromage H, Martin B, James M et al (2017) The Ubiquitination of PINK1 Is Restricted to Its Mature 52-kDa Form. Cell Rep. 20(1):30-39

74. Deas E, Plun-Favreau H, Gandhi S, Desmond H, Kjaer S, Loh SHY et al (2011) PINK1 cleavage at position A103 by the mitochondrial protease PARL. Hum Mol Genet 20(5):867-879

75. Yamano K, Youle RJ (2013) PINK1 is degraded through the N-end rule pathway. Autophagy. 9(11):1758-1769

76. Sekine S, Wang C, Sideris DP, Bunker E, Zhang Z, Youle RJ (2019) Reciprocal roles of Tom7 and OMA1 during mitochondrial import and activation of PINK1. Mol Cell 73(5):1028-1043.e5

77. Guardia-Laguarta C, Liu Y, Lauritzen KH, Erdjument-Bromage H, Martin B, Swayne TC et al (2019) PINK1 content in mitochondria is regulated by ER-associated degradation. J Neurosci 39(36):7074-7085

78. Okatsu K, Uno M, Koyano F, Go E, Kimura M, Oka T et al (2013) A dimeric pink1-containing complex on depolarized mitochondria stimulates parkin recruitment. J Biol Chem 288(51):36372-36384

79. Okatsu K, Oka T, Iguchi M, Imamura K, Kosako H, Tani N et al (2012) PINK1 autophosphorylation upon membrane potential dissipation is essential for Parkin recruitment to damaged mitochondria. Nat Commun. 3:1010-1016

80. Lu W, Karuppagounder SS, Springer DA, Allen MD, Zheng L, Chao B et al (2014) Genetic deficiency of the mitochondrial protein PGAM5 causes a Parkinson's-like movement disorder. Nat Commun. 5(7):4930

81. Wauer T, Komander D (2013) Structure of the human Parkin ligase domain in an autoinhibited state. EMBO J 32(15):2099-2112

82. Chaugule VK, Burchell L, Barber KR, Sidhu A, Leslie SJ, Shaw GS et al (2011) Autoregulation of Parkin activity through its ubiquitin-like domain. EMBO J 30(14):2853-2867

83. Kumar A, Aguirre JD, Condos TE, Martinez-Torres RJ, Chaugule VK, Toth $\mathrm{R}$ et al (2015) Disruption of the autoinhibited state primes the E3 ligase parkin for activation and catalysis. EMBO J 34(20):2506-2521

84. Sauvé V, Lilov A, Seirafi M, Vranas M, Rasool S, Kozlov G et al (2015) A Ubl/ubiquitin switch in the activation of Parkin. EMBO J 34(20):2492-2505

85. Kumar A, Chaugule VK, Condos TEC, Barber KR, Johnson C, Toth $R$ et al (2017) Parkin-phosphoubiquitin complex reveals cryptic ubiquitin-binding site required for RBR ligase activity. Nat Struct Mol Biol 24(5):475-483

86. Wenzel DM, Lissounov A, Brzovic PS, Klevit RE (2011) UBCH7 reactivity profile reveals parkin and HHARI to be RING/HECT hybrids. Nature 474(7349):105-108

87. Park J, Lee SB, Lee S, Kim Y, Song S, Kim S et al (2006) Mitochondrial dysfunction in Drosophila PINK1 mutants is complemented by parkin. Nature 441(7097):1157-1161

88. Clark IE, Dodson MW, Jiang C, Cao JH, Huh JR, Seol JH et al (2006) Drosophila pink1 is required for mitochondrial function and interacts genetically with parkin. Nature 441(7097):1162-1166

89. Pao K, Stanley M, Han C, Lai Y, Murphy P, Wood NT et al (2016) Probes of ubiquitin E3 ligases distinguish different stages of Parkin activation. Nat Chem Biol 12(5):324-331

90. Wauer T, Simicek M, Schubert A, Komander D (2015) Mechanism of phospho-ubiquitin-induced PARKIN activation. Nature 524(7565):370-374

91. Koyano F, Okatsu K, Kosako H, Tamura Y, Go E, Kimura M et al (2014) Ubiquitin is phosphorylated by PINK1 to activate parkin. Nature 510(7503):162-166

92. Kazlauskaite A, Kondapalli C, Gourlay R, Campbell DG, Ritorto MS, Hofmann Ket al (2014) Accelerated publication: Parkin is activated by PINK1-dependent phosphorylation of ubiquitin at Ser65. Biochem J 460(1):127-139 
93. Kane LA, Lazarou M, Fogel Al, Li Y, Yamano K, Sarraf SA et al (2014) PINK1 phosphorylates ubiquitin to activate parkin E3 ubiquitin ligase activity. J Cell Biol 205(2):143-153

94. Kazlauskaite A, Martínez-Torres RJ, Wilkie S, Kumar A, Peltier J, Gonzalez A et al (2015) Binding to serine 65-phosphorylated ubiquitin primes Parkin for optimal PINK 1-dependent phosphorylation and activation. EMBO Rep 16(8):939-954

95. Ordureau A, Sarraf SA, Duda DM, Heo JM, Jedrychowski MP, Sviderskiy VO et al (2014) Quantitative proteomics reveal a feedforward mechanism for mitochondrial PARKIN translocation and ubiquitin chain synthesis. Mol Cell 56(3):360-375

96. Aguirre JD, Dunkerley KM, Mercier P, Shaw GS (2017) Structure of phosphorylated UBL domain and insights into PINK1-orchestrated parkin activation. Proc Natl Acad Sci USA 114(2):298-303

97. Caulfield TR, Fiesel FC, Moussaud-Lamodière EL, Dourado DFAR, Flores SC, Springer W (2014) Phosphorylation by PINK1 releases the UBL domain and initializes the conformational opening of the E3 ubiquitin ligase parkin. PLoS Comput Biol 10(11):e1003935

98. Spratt DE, Julio Martinez-Torres R, Noh YJ, Mercier P, Manczyk N, Barber KR et al (2013) A molecular explanation for the recessive nature of parkin-linked Parkinson's disease. Nat Commun. 4:1-12

99. Safadi SS, Barber KR, Shaw GS (2011) Impact of autosomal recessive juvenile Parkinson's disease mutations on the structure and interactions of the parkin ubiquitin-like domain. Biochemistry 50(13):2603-2610

100. Hampe C, Ardila-Osorio H, Fournier M, Brice A, Corti O (2006) Biochemical analysis of Parkinson's disease-causing variants of Parkin, an E3 ubiquitin — protein ligase with monoubiquitylation capacity. Hum Mo Genet 15(13):2059-2075

101. Heo J-M, Ordureau A, Paulo JA, Rinehart J, Harper JW (2015) The PINK1PARKIN mitochondrial ubiquitylation pathway drives a program of OPTN/NDP52 recruitment and TBK1 activation to promote mitophagy. Mol Cell 60(1):7-20

102. Sarraf SA, Sideris DP, Giagtzoglou N, Ni L, Kankel MW, Sen A et al (2019) PINK1/parkin influences cell cycle by sequestering TBK1 at damaged mitochondria, inhibiting mitosis. Cell Rep 29(1):225-235.e5

103. Vargas JNS, Wang C, Bunker E, Hao L, Maric D, Schiavo G et al (2019) Spatiotemporal control of ULK1 Activation by NDP52 and TBK1 during selective autophagy. Mol Cell 74(2):347-362.e6

104. Nozawa T, Sano S, Minowa-Nozawa A, Toh H, Nakajima S, Murase K et al (2020) TBC1D9 regulates TBK1 activation through $\mathrm{Ca}^{2+}$ signaling in selective autophagy. Nat Commun 11(1):1-16

105. Przedborski S, Vila M, Jackson-Lewis V (2003) Neurodegeneration: what is it and where are we? J Clin Invest 111(1):3-10

106. Hou Y, Dan X, Babbar M, Wei Y, Hasselbalch SG, Croteau DL et al (2019) Ageing as a risk factor for neurodegenerative disease. Nat Rev Neurol 15(10):565-581

107. Cornelissen T, Vilain S, Vints K, Gounko N, Verstreken P, Vandenberghe W (2018) Deficiency of parkin and PINK1 impairs age-dependent mitophagy in drosophila. Elife 7:1-14

108. Fiesel FC, Ando M, Hudec R, Hill AR, Castanedes-Casey M, Caulfield TR et al (2015) (Patho-)physiological relevance of PINK1-dependent ubiquitin phosphorylation. EMBO Rep 16(9):1114-1130

109. Pickrell AM, Huang C-HH, Kennedy SR, Ordureau A, Sideris DP, Hoekstra JG et al (2015) Endogenous parkin preserves dopaminergic substantia Nigral neurons following mitochondrial DNA mutagenic stress. Neuron 87(2):371-382

110. Yeo D, Kang C, Gomez-Cabrera MC, Vina J, Ji LL (2019) Intensified mitophagy in skeletal muscle with aging is downregulated by PGC1alpha overexpression in vivo. Free Radic Biol Med 130:361-368

111. Hou X, Fiesel FC, Truban D, Castanedes Casey M, Lin WL, Soto Al et al (2018) Age- and disease-dependent increase of the mitophagy marker phospho-ubiquitin in normal aging and Lewy body disease. Autophagy 14(8):1404-1418

112. Berman SB, Pineda FJ, Hardwick JM (2008) Mitochondrial fission and fusion dynamics: the long and short of it. Cell Death Differ 15(7):1147-1152

113. Yu W, Sun Y, Guo S, Lu B (2011) The PINK1/Parkin pathway regulates mitochondrial dynamics and function in mammalian hippocampal and dopaminergic neurons. Hum Mol Genet 20(16):3227-3240

114. Evans DA, Funkenstein HH, Albert MS, Scherr PA, Cook NR, Chown MJ et al (1989) Prevalence of Alzheimer's disease in a community population of older persons: higher than previously reported. JAMA, J Am Med Assoc 262(18):2551-2556

115. Deture MA, Dickson DW (2019) The neuropathological diagnosis of Alzheimer's disease. Mol Neurodegener 14(1):1-18

116. Moreira PI, Carvalho C, Zhu X, Smith MA, Perry G (2010) Mitochondrial dysfunction is a trigger of Alzheimer's disease pathophysiology. Biochim Biophys Acta-Mol Basis Dis. 1802(1):2-10

117. Goiran T, Duplan E, Chami M, Bourgeois A, El Manaa W, Rouland L et al (2018) $\beta$-amyloid precursor protein intracellular domain controls mitochondrial function by modulating phosphatase and tensin homologinduced kinase 1 transcription in cells and in alzheimer mice models. Biol Psychiatry 83(5):416-427

118. Checler F, Goiran T, Alves da Costa C (2017) Presenilins at the crossroad of a functional interplay between PARK2/PARKIN and PINK1 to control mitophagy: implication for neurodegenerative diseases. Autophagy. 13(11):2004-2005

119. Bonnet AM, Jutras MF, Czernecki V, Corvol JC, Vidailhet M (2012) Nonmotor symptoms in Parkinsons disease in 2012: relevant clinical aspects. Parkinsons Dis 2012:198316

120. Savitt JM, Dawson VL, Dawson TM (2006) Diagnosis and treatment of Parkinson disease: molecules to medicine. J Clin Invest 116(7):1744-1754

121. Julienne H, Buhl E, Leslie DS, Hodge JJL (2017) Drosophila PINK1 and parkin loss-of-function mutants display a range of non-motor Parkinson's disease phenotypes. Neurobiol Dis 104:15-23

122. Goedert M, Spillantini MG, Del Tredici K, Braak H (2013) 100 years of Lewy pathology. Nat Rev Neurol 9(1):13-24

123. Lee VMY, Trojanowski JQ (2006) Mechanisms of Parkinson's disease linked to pathological a-synuclein: new targets for drug discovery. Neuron 52(1):33-38

124. Oh CK, Sultan A, Platzer J, Dolatabadi N, Soldner F, McClatchy DB et al (2017) S-nitrosylation of PINK1 attenuates PINK1/parkin-dependent mitophagy in hiPSC-based Parkinson's disease models. Cell Rep. 21(8):2171-2182

125. Yao D, Gu Z, Nakamura T, Shi ZQ, Ma Y, Gaston B et al (2004) Nitrosative stress linked to sporadic Parkinson's disease: S-nitrosylation of parkin regulates its E3 ubiquitin ligase activity. Proc Natl Acad Sci USA 101(29):10810-10814

126. Rizza S, Cardaci S, Montagna C, Di Giacomo G, De Zio D, Bordi M et al (2018) S-nitrosylation drives cell senescence and aging in mammals by controlling mitochondrial dynamics and mitophagy. Proc Natl Acad Sci USA 115(15):3388-3397

127. Clark LN, Ross BM, Wang Y, Mejia-Santana H, Harris J, Louis ED et al (2007) Mutations in the glucocerebrosidase gene are associated with early-onset Parkinson disease. Neurology 69(12):1270-1277

128. Lesage S, Bras J, Cormier-Dequaire F, Condroyer C, Nicolas A, Darwent L et al (2015) Loss-of-function mutations in RAB39B are associated with typical early-onset Parkinson disease. Neurol Genet 1(1):e9

129. Wang Y, Liu G, Ping Z, Sun Y, Fang X, Wei H et al (2014) PINK1 and its familial Parkinson's disease-associated mutation regulate brain vascular endothelial inflammation. J Mol Neurosci 53(1):109-116

130. Lockhart PJ, Lincoln S, Hulihan M, Kachergus J, Wilkes K, Bisceglio G et al (2004) DJ-1 mutations are a rare cause of recessively inherited early onset parkinsonism mediated by loss of protein function. J Med Genet 41(3): $1-6$

131. Goldberg MS, Fleming SM, Palacino JJ, Cepeda C, Lam HA, Bhatnagar A et al (2003) Parkin-deficient Mice Exhibit Nigrostriatal Deficits but not Loss of Dopaminergic Neurons. J Biol Chem 278(44):43628-43635

132. Gispert S, Ricciardi F, Kurz A, Azizov M, Hoepken HH, Becker D et al (2009) Parkinson phenotype in aged PINK1-deficient mice is accompanied by progressive mitochondrial dysfunction in absence of neurodegeneration. PLoS ONE 4(6): 57777

133. Itier JM, Ibáñez P, Mena MA, Abbas N, Cohen-Salmon C, Bohme GA et al (2003) Parkin gene inactivation alters behaviour and dopamine neurotransmission in the mouse. Hum Mol Genet 12(18):2277-2291

134. Kitada T, Pisani A, Porter DR, Yamaguchi H, Tscherter A, Martella G et al (2007) Impaired dopamine release and synaptic plasticity in the striatum of PINK1-deficient mice. Proc Natl Acad Sci 104(27):11441-11446

135. Perez FA, Palmiter RD (2005) Parkin-deficient mice are not a robust model of parkinsonism. Proc Natl Acad Sci 102(6):2174-2179 
136. Dave KD, De Silva S, Sheth NP, Ramboz S, Beck MJ, Quang C et al (2014) Phenotypic characterization of recessive gene knockout rat models of Parkinson's disease. Neurobiol Dis 70:190-203

137. Stephenson SEM, Aumann TD, Taylor JM, Riseley JR, Li R, Mann JR et al (2018) Generation and characterisation of a parkin-Pacrg knockout mouse line and a Pacrg knockout mouse line. Sci Rep 8(1):1-11

138. Wang C, Kang X, Zhou L, Chai Z, Wu Q, Huang R et al (2018) Synaptotagmin-11 is a critical mediator of parkin-linked neurotoxicity and Parkinson's disease-like pathology. Nat Commun 9(1):1-14

139. Shin JH, Ko HS, Kang H, Lee Y, Lee YI, Pletinkova O et al (2011) PARIS (ZNF746) repression of PGC-1 a contributes to neurodegeneration in parkinson's disease. Cell 144(5):689-702

140. Brahmachari S, Lee S, Kim S, Yuan C, Karuppagounder SS, Ge P et al (2019) Parkin interacting substrate zinc finger protein 746 is a pathological mediator in Parkinson's disease. Brain 142(8):2380-2401

141. Lee Y, Karuppagounder SS, Shin JH, Lee Y-I, Ko HS, Swing D et al (2013) Parthanatos mediates AIMP2-activated age-dependent dopaminergic neuronal loss. Nat Neurosci 16(10):1392-1400

142. Ko HS, Von Coelln R, Sriram SR, Kim SW, Chung KKK, Pletnikova O et al (2005) Accumulation of the authentic parkin substrate aminoacyl-tRNA synthetase cofactor, p38/JTV-1, leads to catecholaminergic cell death. J Neurosci 25(35):7968-7978

143. Ko HS, Lee Y, Shin JH, Karuppagounder SS, Gadad BS, Koleske AJ et al (2010) Phosphorylation by the c-Abl protein tyrosine kinase inhibits parkin's ubiquitination and protective function. Proc Natl Acad Sci USA 107(38):16691-16696

144. Da Costa CA, Duplan E, Rouland L, Checler F (2018) The transcription factor function of Parkin: breaking the dogma. Front Neurosci 12:965

145. Kao SY (2009) DNA damage induces nuclear translocation of parkin. J Biomed Sci 16(1):1-9

146. Shires SE, Quiles JM, Najor RH, Leon LJ, Cortez MQ, Lampert MA et al (2020) Nuclear Parkin activates the ERRa transcriptional program and drives widespread changes in gene expression following hypoxia. Sci Rep 10(1):1-15

147. Vives-Bauza C, Zhou C, Huang Y, Cui M, De Vries RLA, Kim J et al (2010) PINK1-dependent recruitment of Parkin to mitochondria in mitophagy. Proc Natl Acad Sci USA 107(1):378-383

148. Zhi L, Qin Q, Mugeem T, Seifert EL, Liu W, Zheng S et al (2019) Loss of PINK1 causes age-dependent decrease of dopamine release and mitochondrial dysfunction. Neurobiol Aging 75:1-10

149. Hernández CJ, Báez-Becerra C, Contreras-Zárate MJ, Arboleda H, Arboleda G (2019) PINK1 silencing modifies dendritic spine dynamics of mouse hippocampal neurons. J Mol Neurosci 69(4):570-579

150. McWilliams TG, Prescott AR, Montava-Garriga L, Ball G, Singh F, Barini E et al (2018) Basal mitophagy occurs independently of PINK1 in mouse tissues of high metabolic demand. Cell Metab 27(2):439-449.e5

151. Yang W, Liu Y, Tu Z, Xiao C, Yan S, Ma X et al (2019) CRISPR/Cas9-mediated PINK1 deletion leads to neurodegeneration in rhesus monkeys. Cell Res 29(4):334-336

152. Yang W, Li S, Li XJ (2019) A CRISPR monkey model unravels a unique function of PINK1 in primate brains. Mol Neurodegener 14(1):1-4

153. Matheoud D, Cannon T, Voisin A, Penttinen A-M, Ramet L, Fahmy AM et al (2019) Intestinal infection triggers Parkinson's disease-like symptoms in Pink1 -/- mice. Nature 571(7766):565-569

154. Sulzer D, Alcalay RN, Garretti F, Cote L, Kanter E, Agin-Liebes J et al (2017) T cells from patients with Parkinson's disease recognize a-synuclein peptides. Nature 546(7660):656-661

155. Sommer A, Maxreiter F, Krach F, Fadler T, Grosch J, Maroni M et al (2018) Th17 lymphocytes induce neuronal cell death in a Human iPSC-based model of Parkinson's disease. Cell Stem Cell 23(1):123-131.e6

156. Jiang T, Li G, Xu J, Gao S, Chen X (2018) The challenge of the pathogenesis of Parkinson's disease: is autoimmunity the culprit? Front Immunol 9:2047

157. Garretti F, Agalliu D, Arlehamn CSL, Sette A, Sulzer D (2019) Autoimmmunity in parkinson's disease: the role of a:-synuclein-specific T cells. Front Immunol 10:1-12

158. Amor S, Peferoen LAN, Vogel DYS, Breur M, van der Valk P, Baker D et al (2014) Inflammation in neurodegenerative diseases - an update. Immunology 142(2):151-166
159. Matheoud D, Sugiura A, Bellemare-Pelletier A, Laplante A, Rondeau C, Chemali M et al (2016) Parkinson's disease-related proteins PINK1 and Parkin repress mitochondrial antigen presentation. Cell 166(2):314-327

160. Evans CS, Holzbaur ELF (2019) Autophagy and mitophagy in ALS. Neurobiol Dis 122(215):35-40

161. Fecto F, Yan J, Vemula SP, Liu E, Yang Y, Chen W et al (2011) SQSTM1 mutations in familial and sporadic amyotrophic lateral sclerosis. Arch Neurol 68(11):1440-1446

162. Maruyama H, Morino H, Ito H, Izumi Y, Kato H, Watanabe $Y$ et al (2010) Mutations of optineurin in amyotrophic lateral sclerosis. Nature 465(7295):223-226

163. Freischmidt A, Wieland T, Richter B, Ruf W, Schaeffer V, Müller K et al (2015) Haploinsufficiency of TBK1 causes familial ALS and fronto-temporal dementia. Nat Neurosci 18(5):631-636

164. Knippenberg S, Sipos J, Thau-Habermann N, Körner S, Rath KJ, Dengler Ret al (2013) Altered expression of DJ-1 and PINK1 in sporadic ALS and in the SOD1G93A ALS mouse model. J Neuropathol Exp Neurol 72(11):1052-1061

165. Rosen DR, Siddique T, Patterson D, Figlewicz DA, Sapp P, Hentati A et al (1993) Mutations in Cu/Zn superoxide dismutase gene are associated with familial amyotrophic lateral sclerosis. Nature 362(6415):59-62

166. Lagier-Tourenne C, Polymenidou M, Hutt KR, Vu AQ, Baughn M, Huelga SC et al (2012) Divergent roles of ALS-linked proteins FUS/ TLS and TDP-43 intersect in processing long pre-mRNAs. Nat Neurosci 15(11):1488-1497

167. Neumann M, Sampathu DM, Kwong LK, Truax AC, Micsenyi MC, Chou $T T$ et al (2006) Ubiquitinated TDP-43 in frontotemporal lobar degeneration and amyotrophic lateral sclerosis. Science 314(5796):130-133

168. Roos RAC (2010) Huntington's disease: a clinical review. Orphanet J Rare Dis 5:40

169. Schulte J, Littleton JT (2011) The biological function of the Huntingtin protein and its relevance to Huntington's Disease pathology. Curr Trends Neurol. 5:65-78

170. Franco-Iborra S, Plaza-Zabala A, Montpeyo M, Sebastian D, Vila M, Martinez-Vicente M (2020) Mutant HTT (huntingtin) impairs mitophagy in a cellular model of Huntington disease. Autophagy 1-18. https:// pubmed.ncbi.nlm.nih.gov/32093570/

171. Kim J, Moody JP, Edgerly CK, Bordiuk OL, Cormier K, Smith K et al (2010) Mitochondrial loss, dysfunction and altered dynamics in Huntington's disease. Hum Mol Genet 19(20):3919-3935

172. Shirendeb UP, Calkins MJ, Manczak M, Anekonda V, Dufour B, McBride JL et al (2012) Mutant Huntingtin's interaction with mitochondrial protein Drp1 impairs mitochondrial biogenesis and causes defective axonal transport and synaptic degeneration in Huntington's disease. Hum Mol Genet 21(2):406-420

173. Song W, Chen J, Petrilli A, Liot G, Klinglmayr E, Zhou Y et al (2011) Mutant huntingtin binds the mitochondrial fission GTPase dynaminrelated protein-1 and increases its enzymatic activity. Nat Med 17(3):377-382

174. Squitieri F, Cannella M, Sgarbi G, Maglione V, Falleni A, Lenzi P et al (2006) Severe ultrastructural mitochondrial changes in lymphoblasts homozygous for Huntington disease mutation. Mech Ageing Dev 127(2):217-220

175. Yan S, Tu Z, Liu Z, Fan N, Yang H, Yang S et al (2018) A huntingtin knockin pig model recapitulates features of selective neurodegeneration in Huntington's disease. Cell 173(4):989-1002.e13

176. Gu M, Gash MT, Mann VM, Javoy-Agid F, Cooper JM, Schapira AHV (1996) Mitochondrial defect in Huntington's disease caudate nucleus. Ann Neurol 39(3):385-389

177. Browne SE, Bowling AC, MacGarvey U, Baik MJ, Berger SC, Muqit MMK et al (1997) Oxidative damage and metabolic dysfunction in huntington's disease: selective vulnerability of the basal ganglia. Ann Neurol 41(5):646-653

178. Madeira MH, Boia R, Santos PF, Ambrósio AF, Santiago AR (2015) Contribution of microglia-mediated neuroinflammation to retinal degenerative diseases. Mediators Inflamm 2015:673090

179. Alves CH, Fernandes R, Santiago AR, Ambrósio AF (2020) Microglia contribution to the regulation of the retinal and choroidal vasculature in age-related macular degeneration. Cells 9(5):1217

180. Farinha CVL, Cachulo ML, Alves D, Pires I, Marques JP, Barreto P et al (2019) Incidence of age-related macular degeneration in the central 
region of Portugal: the Coimbra eye study-report 5. Ophthalmic Res 61(4):226-235

181. Cachulo MDL, Lobo C, Figueira J, Ribeiro L, Laíns I, Vieira A et al (2015) Prevalence of age-related macular degeneration in Portugal: the Coimbra eye study-report 1. Ophthalmologica 233:119-127

182. Karunadharma PP, Nordgaard CL, Olsen TW, Ferrington DA (2010) Mitochondrial DNA damage as a potential mechanism for age-related macular degeneration. Investig Ophthalmol Vis Sci. 51 (11):5470-5479

183. Felszeghy S, Viiri J, Paterno JJ, Hyttinen JMT, Koskela A, Chen M et al (2019) Loss of NRF-2 and PGC-1 a genes leads to retinal pigment epithelium damage resembling dry age-related macular degeneration. Redox Biol 20:1-12

184. Gupta N, Yücel YH (2007) Glaucoma as a neurodegenerative disease. Curr Opin Ophthalmol 18(2):110-114

185. Tham YC, Li X, Wong TY, Quigley HA, Aung T, Cheng CY (2014) Global prevalence of glaucoma and projections of glaucoma burden through 2040: a systematic review and meta-analysis. Ophthalmology 121(11):2081-2090

186. Weinreb RN, Khaw PT (2004) Primary open-angle glaucoma. Lancet 363(9422):1711-1720

187. Heijl A, Leske MC, Bengtsson B, Hyman L, Bengtsson B, Hussein M et al (2003) Reduction of intraocular pressure and glaucoma progression. Evidence-Based Eye Care 4(3):137-139

188. Nguyen D, Alavi MV, Kim KY, Kang T, Scott RT, Noh YH et al (2011) A new vicious cycle involving glutamate excitotoxicity, oxidative stress and mitochondrial dynamics. Cell Death Dis 2(12):1-10

189. Hu X, Dai Y, Sun X (2017) Parkin overexpression protects retinal ganglion cells against glutamate excitotoxicity. Mol Vis 23:447-456

190. Chernyshova K, Inoue K, Yamashita S-I, Fukuchi T, Kanki T (2019) Glaucoma-associated mutations in the optineurin gene have limited impact on parkin-dependent mitophagy. Invest Opthalmol Vis Sci 60(10):3625

191. Wong YC, Holzbaur ELF (2014) Optineurin is an autophagy receptor for damaged mitochondria in parkin-mediated mitophagy that is disrupted by an ALS-linked mutation. Proc Natl Acad Sci USA 111(42):4439-4448

192. Valente EM, Salvi S, lalongo T, Marongiu R, Elia AE, Caputo V et al (2004) PINK1 mutations are associated with sporadic early-onset parkinsonism. Ann Neurol 56(3):336-341

193. Mouton-Liger F, Rosazza T, Sepulveda-Diaz J, leang A, Hassoun SM, Claire E et al (2018) Parkin deficiency modulates NLRP3 inflammasome activation by attenuating an A20-dependent negative feedback loop. Glia 66:1736-1751

194. Sliter DA, Martinez J, Hao L, Chen X, Sun N, Fischer TD et al (2018) Parkin and PINK1 mitigate STING-induced inflammation. Nature 561 (7722):258-262

195. Kim J, Byun J-W, Choi I, Kim B, Jeong H-K, Jou I et al (2013) PINK1 deficiency enhances inflammatory cytokine release from acutely prepared brain slices. Exp Neurobiol 22(1):38

196. Moriya S, Tan VP, Yee AK, Parhar IS (2019) pink1, atp13a2 and uchl1 expressions are affected by inflammation in the brain. Neurosci Lett 708:134330

197. Trifunovic A, Wredenberg A, Falkenberg M, Spelbrink JN, Rovio AT, Bruder CE et al (2004) Premature ageing in mice expressing defective mitochondrial DNA polymerase. Nature 429(6990):417-423

198. Chen Q, Sun L, Chen ZJ (2016) Regulation and function of the CGAS-STING pathway of cytosolic DNA sensing. Nat Immunol 17(10):1142-1149

199. Kerur N, Fukuda S, Banerjee D, Kim Y, Fu D, Apicella I et al (2018) CGAS drives noncanonical-inflammasome activation in age-related macular degeneration. Nat Med 24(1):50-61

200. West AP, Khoury-Hanold W, Staron M, Tal MC, Pineda CM, Lang SM et al (2015) Mitochondrial DNA stress primes the antiviral innate immune response. Nature 520(7548):553-557
201. Lee JJ, Andreazza S, Whitworth AJ (2020) The STING pathway does not contribute to behavioural or mitochondrial phenotypes in Drosophila Pink1/parkin or mtDNA mutator models. Sci Rep. 10(1):2693

202. Gkirtzimanaki K, Kabrani E, Nikoleri D, Polyzos A, Blanas A, Sidiropoulos $P$ et al (2018) IFNa impairs autophagic degradation of mtDNA promoting autoreactivity of SLE monocytes in a STING-dependent fashion. Cell Rep 25(4):921-933.e5

203. Frank-Cannon TC, Tran T, Ruhn KA, Martinez TN, Hong J, Marvin M et al (2008) Parkin deficiency increases vulnerability to inflammation-related nigral degeneration. J Neurosci 28(43):10825-10834

204. Wilhelmus MMM, Van Der Pol SMA, Jansen Q, Witte ME, Van Der Valk P, Rozemuller AJM et al (2011) Association of Parkinson disease-related protein PINK1 with Alzheimer disease and multiple sclerosis brain lesions. Free Radic Biol Med 50(3):469-476

205. Witte ME, Bol JGJM, Gerritsen WH, van der Valk P, Drukarch B, van Horssen J et al (2009) Parkinson's disease-associated parkin colocalizes with Alzheimer's disease and multiple sclerosis brain lesions. Neurobiol Dis 36(3):445-452

206. Sun L, Shen R, Agnihotri SK, Chen Y, Huang Z, Büeler H (2018) Lack of PINK1 alters glia innate immune responses and enhances inflammation-induced, nitric oxide-mediated neuron death. Sci Rep 8(1):383

207. Choi I, Kim J, Jeong HK, Kim B, Jou I, Park M et al (2013) PINK1 deficiency attenuates astrocyte proliferation through mitochondrial dysfunction, reduced AKT and increased p38 MAPK activation, and downregulation of EGFR. Glia 61(5):800-812

208. Dionísio PEA, Oliveira SR, Amaral JSJD, Rodrigues CMP (2018) Loss of microglial parkin inhibits necroptosis and contributes to neuroinflammation. Mol Neurobiol 63(4):2990-3004

209. Tran TA, Nguyen AD, Chang J, Goldberg MS, Lee JK, Tansey MG (2011) Lipopolysaccharide and tumor necrosis factor regulate parkin expression via Nuclear factor-kappa B. PLoS ONE 6(8):e23660

210. de Léséleuc L, Orlova M, Cobat A, Girard M, Huong NT, Ba NN et al (2013) PARK2 mediates interleukin 6 and monocyte chemoattractant protein 1 production by human macrophages. PLoS Negl Trop Dis 7(1):e2015

211. Alves CH, Wijnholds I (2018) AAV-mediated gene therapy for CRB1hereditary retinopathies. Intechopen 6:1-20

212. Bian M, Liu J, Hong X, Yu M, Huang Y, Sheng Z et al (2012) Overexpression of parkin ameliorates dopaminergic neurodegeneration induced by 1- methyl-4-phenyl-1,2,3,6-tetrahydropyridine in mice. PLOS ONE 7(6):e39953

213. Moskal N, Riccio V, Bashkurov M, Taddese R, Datti A, Lewis PN et al (2020) ROCK inhibitors upregulate the neuroprotective Parkin-mediated mitophagy pathway. Nat Commun 11(1):1-14

214. Wang H, Zhang T, Ge X, Chen J, Zhao Y, Fu J (2020) Parkin overexpression attenuates AB-induced mitochondrial dysfunction in HEK293 cells by restoring impaired mitophagy. Life Sci 244:117322

215. Hong X, Liu J, Zhu G, Zhuang YH, Suo H, Wang P et al (2014) Parkin overexpression ameliorates hippocampal long-term potentiation and $\beta$-amyloid load in an Alzheimer's disease mouse model. Hum Mol Genet 23(4):1056-1072

\section{Publisher's Note}

Springer Nature remains neutral with regard to jurisdictional claims in published maps and institutional affiliations. 